\title{
Do contrastive topics exist? ${ }^{1}$ \\ ELENA TITOV \\ $U C L$
}

\begin{abstract}
This paper investigates a phenomenon that has been referred to in the linguistic literature as Contrastive Topic. Traditionally, Contrastive Topic is analysed as an independent information-structural notion that is linked to a particular interpretation and intonation. The paper, however, argues that the information-structural notion of Contrastive Topic is redundant and can be reduced to that of Contrastive Focus. The apparent dissimilarity between Contrastive Topics and Contrastive Foci is attributed to a difference in the structures that contain them rather than any particular difference between the associated information-structural notions themselves. The structures that host Contrastive Topics and Contrastive Foci are claimed to be distinct due to the nature of an additional focused element obligatorily present in the sentence. Contrastive Topics and Contrastive Foci themselves, in contrast, are shown to be associated with identical interpretations, which results in their identical syntactic distribution, strongly suggesting that they in fact represent one and the same information-structural phenomenon in two different types of construction.
\end{abstract}

\section{INTRODUCTION}

This paper investigates a phenomenon that has been referred to in the linguistic literature as CONTRAstive TOPIC (henceforth CT). (Examples of CTs are given in (1) and (2).) Traditionally CT is analysed as an independent INFORMATION STRUCTURAL (henceforth IS) notion that is linked to a particular interpretation and intonation.

The interpretation that CTs are associated with has been characterized as that of incompleteness or of a set of sets of propositions/ questions (Büring 2003). Thus, the sentences in (1) and (2) cannot be construed as offering a full answer to the questions in the context. Instead, they leave the impression that more needs to be said (as suggested by the continuations in the brackets). In (1), information is requested about John, whereas the reply asserts that the proposition $x$ ate the beans is true of Fred but does not say anything about John. Similarly, in (2), the reply conveys that the proposition Fred ate $x$ holds of the beans but it has nothing to say about the soup. (Throughout, the word that bears the main sentential stress is given in bold).

(1) [What did John eat?] ConTEXT

$[\text { Fred }]_{\text {CT }}$ ate [the beans $]_{\text {FOC ... (but I don't know about John) }}$

(2) [Who ate the soup?] CONTEXT

$[\text { Fred }]_{\text {FOC }}$ ate $[\text { the beans }]_{\text {CT }}$... (but I don't know about the soup)

In many languages CTs are marked with a rising intonational contour. In English, they carry a (fall)-rise contour, dubbed the B-accent by Jackendoff (1972). In Russian, CTs are characterized by a rise in pitch on the stressed vowel, a contour sometimes referred to as IK3 (Bryzgunova 1971, 1981). In German, Top/Foc structures are marked with a so-called hat (or bridge) contour, with a rise on the CT and a fall on the focus. Moreover, unlike in English, in German and Russian CTs undergo fronting (see (4) for a Russian example). 
(3) [What did Ivan eat?] CONTEXT

$[\text { Boris }]_{\mathrm{CT}}$ el $[\text { boby }]_{\mathrm{FOC}}$ (a nasčët Ivana ne znaju)

Boris ate beans-ACC (but I don't know about Ivan)

'Boris ate the beans (but I don't know about Ivan).'

(4) [Who ate the soup?]CONTEXT

$[\text { Boby }]_{\mathrm{CT}}$ el $[\text { Boris }]_{\mathrm{FOC}}$ (a nasčët supa ne znaju)

beans-ACC ate Boris (but I don't know about the soup)

'Boris ate the beans (but I don't know about the soup).'

My aim is to argue that the IS notion of CT is redundant and can be reduced to that of CONTRASTIVE FocUs (henceforth CF). An example of CF is given in (5).

(5) [Fred ate the beans. $]_{\text {CONTEXT }}$

(No) Fred ate the $[\text { soup }]_{\mathrm{CF}}$ (not the beans)

At first glance, CFs seem quite distinct from CTs, as they carry a distinct intonational contour and are associated with a distinct interpretation. CFs are marked with falling intonation (Jackendoff's 1972 A-accent and Bryzgunova's 1971, 1981 IK2) and utterances containing CFs do not convey an interpretation of incompleteness, but rather that of opposition or counter-assertion to the proposition in the context. ${ }^{2}$

However, I will argue that the apparent dissimilarity between CTs and CFs is due to a difference between the structures that contain them rather than any particular difference between the associated IS notions themselves. The structures that host CTs and CFs will be claimed to differ in the nature of an additional focused element obligatorily present in the sentence. CTs and CFs themselves, in contrast, will be shown to be associated with identical interpretations, which results in their identical syntactic distribution, strongly suggesting that they in fact represent one and the same IS phenomenon in two different types of construction. The analysis is based on data from Russian and English but is assumed to extend to other languages.

The suggestion that CT is a focus-like element is not entirely novel; related ideas can be found in Sauerland (2005), Irurtzun (2007), Wagner (2008, 2009, to appear) and Tomioka (2010). What distinguishes the present analysis from previous accounts is the claim that it is the divergent properties of an additional focused element that differentiates structures hosting either a CT or a CF.

The paper is organized as follows: Section 2 examines the distribution of Russian non-contrastive foci; Section 3 establishes the definition of contrast and looks at the distribution of contrastive categories; Section 4 discusses the similarities and differences between CT and CF and spells out the nature of the additional focused element in sentences that contain them; Section 5 discusses the semantics of certain focus-sensitive operators and their incompatibility with the semantics of sentences containing a CT; Section 6 concludes the paper.

\section{The Distribution OF NON-CONTRASTIVE FOCUS IN RUSSIAN}

I will assume two binary interpretative features, [ \pm presupposed] and [ \pm contrastive], to characterize the information-structural categories I discuss in the paper. A key hypothesis on which my analysis will rely is that $\mathrm{CT}, \mathrm{CF}$ and non-contrastive focus all share the feature [-presupposed]. 
While the above features are not intended as syntactic, but merely specify interpretative properties of the categories that carry them, this is not to say that they do not have any impact on the distribution of these categories. However, I will argue that these distributive effects come about as a result of mapping principles that relate syntactic structures to IS interpretations.

In this section, I consider the distribution of [-presupposed] material and propose a mapping principle that captures the observation that non-contrastive focus in Russian consistently surfaces in clause final position. As a null hypothesis, I propose that Russian is subject to the generalization introduced by Neeleman \& Titov (2009). A slightly modified version of it is given in (6). ${ }^{3}$

(6) [-presupposed] categories are licensed in clause final position

Admittedly, this generalization does not hold on the surface. Non-contrastive focus must indeed show up clause-finally, as illustrated in (7). ${ }^{4}$ But contrastive categories typically occupy positions further to the left, as shown below (see Krylova \& Khavronina 1988, King 1995, and Brun 2001). Nevertheless, as will be argued in section 3, the launching site for the movement of contrastive categories is the position in which noncontrastive focus must surface.

(7) (a) [What does Anna read? $]_{\text {CONTEXT }}$

Anja čitaet $[\mathbf{k n i g u}]_{\mathrm{FOC}}$

Anna reads book-ACC

'Anna reads the/a book.'

(b) [Who reads the/a book? $]_{\text {CONTEXT }}$

$\begin{array}{lll}\text { Knigu čitaet } & \text { [Anja }]_{\text {FOC }} & O V[S]_{F}\end{array}$

book-ACC reads Anna

'Anna reads the/a book.'

(c) [Who did Anna give a book to? $]_{\text {CONTEXT }}$

Anja dala knigu [Kate $]_{\mathrm{FOC}}$

Anna gave book-ACC Catherine-DAT

$\mathrm{SVO}[\mathrm{IO}]_{\mathrm{F}}$

'Anna gave a book to Catherine.'

(d) [What did Anna give to Catherine? $]_{\text {CONTEXT }}$

$\begin{array}{lll}\text { Anja dala Kate } \quad \text { SVIO }[\mathrm{OO}]_{\mathrm{F}} & \end{array}$

Anna gave Catherine-DAT book-ACC

'Anna gave a book to Catherine.'

It must be noted that the term PRESUPPOSITION has traditionally been used to describe two separate phenomena: in semantics, it refers to a condition that has to be fulfilled for a sentence to be either true or false; in works on Information Structure, it denotes the background of a sentence (see for example Lambrecht's 1994 PRAGMATIC PRESUPPOSITION). ${ }^{5}$ Here, I use the term presupposition in its latter definition. Hence, the focus of a sentence is [-presupposed], whereas the background is [+presupposed]. ${ }^{6,7}$

In (7), the sentences are divided into background and focus, with the background consisting of presupposed material and the focus offering non-presupposed information. For instance, in (7a), the question in the context presupposes that Anna reads something but it is not known what exactly, whereas the answer contains a non-presupposed part 
that fulfils the background and turns it into a true proposition (Büring 1997). In short, the non-presupposed constituent in (7a) provides a value for $x$ in Anna reads $x$.

The examples in (7) contain a non-contrastive or so-called NEW INFORMATION FocUs (henceforth NIF). In Russian, such foci are marked with a falling intonation (IK1), similar to IK2 assigned to CF, but slightly lower-pitched and less intense (Bryzgunova 1971, 1981). They are either not linked to anything in the preceding discourse, or, when used in a question-answer context, are linked to a wh-phrase.

The word order variation found in Russian sentences with non-contrastive focus exhibits properties of A-scrambling (Titov 2007). ${ }^{8}$ That is, it feeds anaphoric binding (see $(8 \mathrm{a}, \mathrm{b}))^{9}$, does not give rise to weak crossover effects (see (9)), is clause-bounded (not demonstrated here), and does not give rise to scope-reconstruction (see (10)). ${ }^{10}$

(a) *Vystrely drug druga 1 ubili

killed

milicionerov 1

SVO

(b) Milicionerov ${ }_{1}$ ubili vystrely drug druga 1

Milicionerov $_{1} \quad$ ubili vystrely $\quad$ drug druga 1

milicia-men-ACC

milicia-men-ACC killed shots-NOM each other-GEN

'Milicia men were killed by each others shots.'

(9)

$\begin{array}{lllll}\text { Každuju } & \text { devočku } & \text { ljubit } & \text { eë } & \text { mama } \\ \text { every } & \text { girl-ACC } & \text { loves } & \text { her } & \text { mum }\end{array}$

'Every girl is loved by her mum.'
(a) Každuju otkrytku podpisali [dva studenta $]_{\mathrm{NIF}}$ every postcard-ACC signed two students

'Every postcard was signed by two students.' $\quad \forall>\exists ; ? \exists>\forall$
(b)

$\begin{array}{llll}\text { Dve } & \text { otkrytki } & \text { podpisal } & {[\text { každyj }} \\ \text { two } & \text { postcards-ACC } & \text { signed } & \text { every }\end{array}$
'Two postcards were signed by every student.'
student $]_{\mathrm{NIF}}$
student
$\exists>\forall ; * \forall>\exists$

It has been claimed that scope reconstruction and WCO effects are unreliable tests for an A-position in Russian because it has so-called 'frozen' scope and obviates WCO effects in general (King 1995, Ionin 2001, Bailyn p.c., 2004a). However, the examples in (11) below demonstrate that WCO violations and scope reconstruction obtain whenever an A'-moved quantifier undeniably crosses an argument, suggesting that scrambled sentences taken to have 'frozen' scope or to lack WCO violations involve reconstruction of an A'-moved object to an A-position above the sentence-final focused subject, as in (12) below (Titov 2007).

(a)

[Who does her mum want to kiss every girl?]CONTEXT

* [Každuju devočku], eё 1 mama xočet, every girl-ACC her mum wants

čtoby $t_{1}$ poceloval Ivan

that kissed Ivan

(b) [Who do two boys want to kiss every girl?]CONTEXT
[Každuju devočku], dva mal'čika xotjat, every girl-ACC two boys want
čtoby $t_{1}$ poceloval Ivan
that kissed Ivan

(12) [Who does Ivan want to kiss every girl?] 
(a)

$\begin{array}{llll}\text { [Každuju } & \text { devočku }]_{1}, & \text { Ivan } & \text { xočet, } \\ \text { every } & \text { girl-ACC } & \text { you } & \text { want } \\ \text { čtoby } t_{1} & \text { pocelovala } & \text { eë } & \text { mama } \\ \text { that } & \text { kissed } & \text { her } & \text { mum }\end{array}$

(b)

'Ivan wants every girl to be kissed by her mum.'

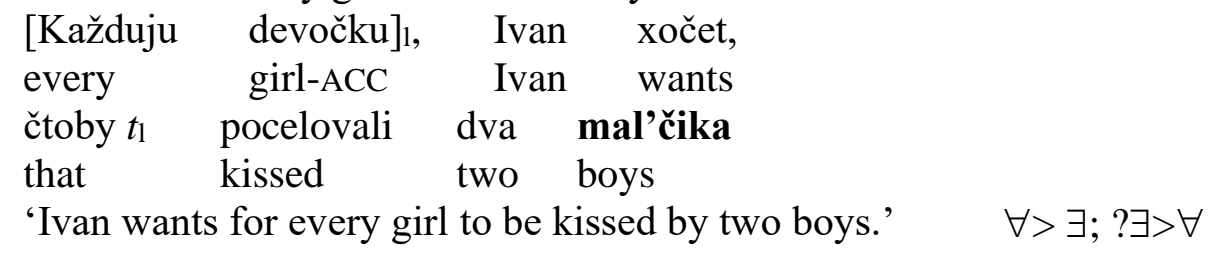

Russian A-scrambling can be analysed as resulting from either A-movement (King 1995 and Bailyn 2004a) or variation in the base component (Titov 2007). ${ }^{11}$ However, to sustain the former analysis, it must be stipulated that there is no scope reconstruction in A-chains. ${ }^{12}$ Regardless of the approach taken, base-generation or A-movement with no scope reconstruction, A-scrambled structures are marked with respect to those exhibiting canonical order (compare Last Resort, Chomsky 1995). ${ }^{13}$ Since unmarked and marked structures coexist in the language, economy considerations demand that the latter is created only to capture an interpretation the former fails to convey. In short, a marked structure must receive an interpretative license (cf. Neeleman \& van de Koot 2008).

The interpretative license for Russian scrambled constructions can be provided by a mapping rule that relates syntactic structures to IS representations with the outcome that an argument in a scrambled position is interpreted as prominent unlike the argument it scrambles across:

\section{Argument prominence mapping rule}

Interpret an A-scrambled structure as reflecting the relative prominence of two arguments, where an argument in a scrambled position is construed as [+prominent] and an argument in the position across which scrambling takes place as [-prominent].

I would like to argue that in scrambling languages, like Russian, the relative prominence of arguments can be established on the basis of not only theta prominence but also discourse prominence; with the former predicting the unmarked order of arguments and the latter licensing scrambled orders. That is, an argument can be construed as either [+prominent] or [-prominent] on the basis of the discourse interpretation it is linked to. An argument associated with an interpretation already present in a discourse can be understood as made prominent through context, whereas an argument that conveys information that is not yet part of the Common Ground cannot. If so, the generalization in (6) can be understood as resulting from the rule in (13), as the relative prominence of arguments must be reflected by the linear precedence of the prominent [+presupposed] argument with respect to the non-prominent [-presupposed] argument. Moreover, given the right-branching structure of Russian clauses, the mapping rule also determines that a prominent argument outscopes a non-prominent one (see (10)). ${ }^{14}$

The rule in (13) does not only account for the relative order of a [+presupposed] argument with respect to a [-presupposed] argument; it also regulates the order of [-presupposed] arguments when one is linked to a non-identical discourse antecedent while the other is unlinked, as in (4). By hypothesis, the relative discourse-prominence of 
such arguments is established on the basis of the [ $\pm \mathrm{D}$-linked] feature. This is because an indirect D-link can be understood as a contributing factor to discourse prominence: a category that has a link to a member of a set to which this category itself belongs can be understood as discourse-prominent unlike the unlinked category.

Since the mapping rule in (13) interprets A-scrambled structures as respecting argument prominence, it predicts that when the relative prominence of [-presupposed] arguments is established on the basis of the [ \pm D-linked] feature, objects with the interpretation of CT A-scramble above subjects that belong to NIF in Top/Foc structures like (4). ${ }^{15}$ Yet, contrastive constituents undergo A'-fronting in a variety of languages, including Russian, thereby making it difficult to establish whether the object with the interpretation of CT in (4) was generated in its default position or in an A-scrambled position above the subject. This issue can be settled, however, on the basis of scope, given that A'-movement obligatorily reconstructs for scope. ${ }^{16}$ That is, A'-movement from the default position would result in the object being interpreted below the subject. Conversely, if an A-scrambled structure that is licensed by (13) serves as the input for subsequent A'-movement of the [+contrastive] object, a sentence like (4) will exhibit surface scope only. As can be seen from (14), the scopal readings support the idea that an A-scrambled structure is formed prior to A'-movement of the CT:

(14) (a) [Who do you want to sign every envelope?]CONTEXT [Každuju otkrytku $]_{\mathrm{CT} 1}, \quad$ ja xoču, čtoby $t_{1}$ podpisali [every postcard]-ACC I want that signed [dva studenta $]_{\mathrm{NIF}}$ (a nasčët každogo konverta ne znaju) two students (and about every envelope not know) 'Every postcard I want to be signed by two students (but I don't know about every envelope.' $\forall>\exists ; ? \exists \forall$

(b) [Who do you want to sign two envelopes? $]_{\text {CONTEXT }}$
[Dve otkrytki] $]_{\mathrm{CT} 1}, \quad$ ja xoču, čtoby $t_{1}$ podpisal [two postcards]-ACC I want that signed

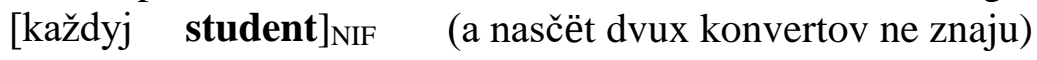 every student (and about two envelopes not know) 'Two postcards I want to be signed by every student (but I don't know about two envelopes).'
$\exists>\forall ; * \forall>\exists$

The next section looks in more detail at the distribution of contrastive categories with the aim to provide a coherent definition of contrast that captures the differences in the syntactic behaviour between contrastive and non-contrastive constituents in Russian.

\section{CONTRAST ${ }^{17}$}

\subsection{What does it mean to be contrastive?}

The standard assumption in the literature on IS is that for a constituent to be interpreted as contrastive it must be construed as belonging to a contextually salient set of alternatives (Halliday 1967, Jackendoff 1972, Chafe 1976, Rooth 1985, and Rooth 1992). I will refer to a set of contextually salient alternatives as a PRAGMATIC SET OF ALTERNATIVES, as opposed to a semantic set of alternatives, which is usually taken to form the basis for the interpretation of foci generally (Krifka 2008). Unlike a semantic set, a pragmatic set of 
alternatives is relevant specifically for the discourse under consideration. The hypothesis put forward here is that, although the semantic interpretation of focus might involve selection from a set, for a focus to be contrastive, the set of alternatives must become active in the discourse at the point the sentence containing the contrastive element is uttered. NO SOONER AND NO LATER. That is, it must be indicated either through a link to the context or within the utterance itself that the set to which the focused constituent belongs indeed contains alternative members that are relevant for the discourse at hand. Thus, the focused object NPs in (15) are NOT contrastive because no contextually salient set of alternatives is available for them.
[Who did Ivan feed?]CONTEXT
(a) Ivan pokormil [kota $]_{\mathrm{NIF}}$
Ivan fed cat-ACC
'Ivan fed the cat.'
(b) $[\text { Boris }]_{\mathrm{CT}}$ pokormil $[\text { kota }]_{\mathrm{NIF}}$ (a nasčët Ivana ne znaju)
Boris fed cat-ACC (but I don't know about Ivan)
'Boris fed the cat (but I don't know about Ivan).'

The NIF cat provides a value for a variable introduced by the wh-phrase in the context, but it is not indicated either through a link to the context or within the utterance itself that there are alternative members of the set to which cat belongs that are relevant for the discourse at hand. That is, it is not made explicit by the utterances in (15) that for the proposition $y f e d x$, more than one entity is competing for $x$. Importantly, the interpretation of a non-contrastive focus is not necessarily exhaustive and further members of the set to which cat in (15) belongs can be added in the following discourse. What is crucial for the non-contrastive reading is merely that the utterance containing a non-presupposed element DOES NOT pragmatically 'activate' a set that contains the non-presupposed element along with alternative members.

Similarly, in (16), the object is [-contrastive] as the set to which it belongs and which contains at least two members is salient BEFORE the sentence is uttered. ${ }^{18,19}$

[Did Ivan feed the cat or the dog? $]_{\text {CONTEXT }}$
Ivan pokormil $[\text { kota }]_{\mathrm{NIF}}$
Ivan fed cat-ACC
'Ivan fed the cat.'

RU

In (16), the reply DOES NOT activate the interpretation that sees the object as belonging to a pragmatic set; this interpretation is already activated by the contextual question. Hence, the object is interpreted as [-presupposed], [+D-linked] and [-contrastive].

Conversely, in (17) and (18a), the [-presupposed] constituents MUST be construed as contrastive: In (17), the proposition Ivan fed $x$ has two contextually salient members of a set that compete for $x, \operatorname{dog}$ and cat. This set is not activated until the mention of $c a t$ in the answer. ${ }^{20}$

[Did Ivan feed the dog?] CONTEXT

RU

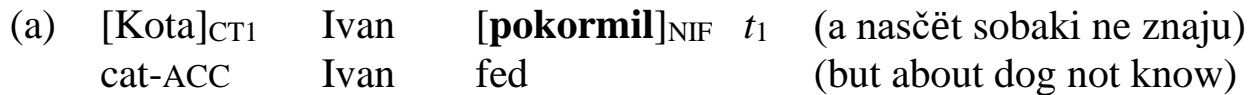

'Ivan fed the cat (but I don't know about the dog).'

(b) (Net,) Ivan [kota $]_{\mathrm{CF} 1}$ pokormil $t_{1} \quad$ (a ne sobaku) 
(no) Ivan cat-ACC fed (and not dog)

'Ivan fed the cat (not the dog).'

In (18), the question in the context contains a plural noun. The reply in (18a) treats this noun as generalizing over a set of animals to which cat belongs along with alternative members. Importantly, the construal of the noun animals in the context as generalizing over a set of alternatives is activated by the sentence that contains cat and not by the contextual question itself. The following discourse can treat this noun as a member of a set of alternatives (see (18b)), or refer back to it without invoking contrast, as in (18c).

[Did Ivan feed the animals?]CONTEXT

RU

(a) $[\text { Kota }]_{\mathrm{CT} 1}$ Ivan [pokormil $]_{\mathrm{NIF}} t_{1}$, cat-ACC Ivan fed

(a nasčët ostal'nyx životnyx ne znaju)

(but about remaining animals not know)

'Ivan fed the cat (but I don't know about the rest of the animals).'

(b) Net, Ivan $\quad[\text { ljudej }]_{\mathrm{CF} 1}$ pokormil $t_{1}$

no Ivan humans-ACC fed

'No, Ivan fed the humans.'

(c) Da, Ivan [pokormil $]_{\mathrm{NIF}}$ životnyx

yes Ivan fed animals-ACC

'Yes, Ivan fed the animals.'

Crucially, the set of alternatives to which the object cat belongs in (17) and (18a) becomes active at the point the utterances containing it are produced, NO SOONER AND NO LATER. The construal of contrastive constituents in (17) and (18a) is not exhaustive (the cat is not necessarily construed as the ONLY animal being fed by Ivan), suggesting that the set for a CT and CF is NOT closed (contra Halliday 1967, Chafe 1976, Rooth 1992 and Kiss 1998). What distinguishes the contrastive constituents in (17) and (18a) from NIFs in (15) and (16) is not the closed/open status of the semantic set they belong to but the fact that the utterance that hosts the former activates the interpretation that the set they belong to contains alternative members relevant for the discourse at hand, whereas the utterance hosting the latter either refers back to an already introduced set, as in (16), or treats the NIF as the only member of its pragmatic set (see (15)).

As mentioned, Russian contrastive constituents may undergo A'-fronting. Notably, the focused objects in (15) and (16) have to remain in situ (in their default postverbal positions), strongly suggesting that they are not contrastive. Conversely, in (17) and (18a), the [+contrastive] constituents move (although not demonstrated here, they can also undergo long-distance movement).

Membership of a pragmatic set of alternatives can be indicated not only through a link to an alternative member of a set in the context, as in (17), or a superset, as in (18a); it can also be specified with the help of a special marker. Attachment of either a prosodic marker, the B-accent, (see (19a)) or a morphological marker -TO (see (19b)) to a discourse-anaphoric subject activates the interpretation that there is at least one more member of the set it belongs to that is significant for the exchange at hand.

[What did the teachers drink at the party?]CONTEXT

(a) $[\text { The teachers }]_{\mathrm{CT}}$ drank $[\text { water }]_{\mathrm{NIF}}$, 
$\mathrm{L}+\mathrm{H}^{*} \mathrm{LH} \%$

(but I am wondering what the students drank)

(b) [Učitelja-to $]_{\mathrm{CT}}$ pili $[\text { vodu }]_{\mathrm{NIF}}$,

RU

teachers-TO drank water-ACC

(a vot interesno, čto studenty pili)

(but interesting what students drank).

'The teachers drank water (but I wonder what the students drank).

In (19), membership of a pragmatic set of alternatives is signalled not through a link to the preceding context but by a property of the utterance itself. Similarly, sentences containing a so-called EMPHATIC FOCUS (henceforth EF) also activate the interpretation that the focus belongs to a pragmatic set of alternatives but this time via its marked structural position:

(a) [Who did you just see?] CONTEXT

RU

(Predstavljaeš',)

(Imagine)

ja tol'ko čto [čeloveka $\mathrm{s}$ ruž'ëm $]_{\mathrm{FOC} 1}$ videl $t_{1}$ !

I just man-ACC with gun saw

'(Can you imagine?) I just saw the/a man with the/a gun!'

(b) [What are you fishing for? $]_{\text {CONTEXT }}$

Ja $\quad[\mathbf{r y b u}]_{\mathrm{FOC} 1}$ lovlju $t_{1}$ (čto že eščë)!

I fish-ACC catch (what else)

'I'm fishing for fish (what else can I be fishing for)!'

Here, a [-presupposed] constituent cannot be interpreted as NIF because, unlike noncontrastive focus, it surfaces in a preverbal position. Yet, the contrastive interpretation is not due to the context. Crucially, the focus in (20) must be construed as occupying a certain scalar position with respect to all alternatives in the set it belongs to. Logically, only two such positions can be indicated when the alternative members stay implicit, the lowest and the highest. On the first reading, the [-presupposed] constituent is interpreted as the weakest member of the set (see (20a)); the second reading, in contrast, interprets the focused object as the strongest member of its set (see (20b)).

The lowest scalar position of the non-presupposed constituent in a set of alternatives in (20a) conveys surprise as to the fact that out of a set of individuals the speaker expected to see, it was the least expected man with the gun that was seen. The interpretation of the non-presupposed object in (20b) is the directly opposite one. This time the focused constituent is perceived as the strongest member as regards all other potential members of the set of alternatives. That is, out of the set of objects that one can be expected to be fishing for, fish is the most obvious choice. It can therefore be said that in (20b) the interpretation is not that of surprise but rather of annoyance as to the fact that one is asked a question that has a rather obvious answer.

Since EF often occurs out of the blue or in a context that does not force a contrastive interpretation (see (20)), it has traditionally not been grouped together with contrastive categories. However, EF must be interpreted as belonging to a pragmatic set of alternatives. This is achieved through shared knowledge of interlocutors about the scalar position of the focused constituent with respect to potential alternatives. ${ }^{21}$ Plausibly, no item can be perceived as occupying either the highest or the lowest position in a set 
lacking alternative members. Since these must become active in the discourse for such an interpretation to be available, our definition of contrast suggests that such foci must be analysed as [+contrastive] and grouped together with CFs.

The analysis of contrast as membership of a pragmatic set of alternatives activated by the utterance containing the relevant non-presupposed element groups CT, CF and EF together as contrastive, whereas simple NIF must be analysed as [-contrastive]. At the same time, all these categories are interpreted as [-presupposed]. In the majority of cases, they consist of discourse-new material, and can therefore not be construed as belonging to the background of a sentence. Moreover, in the rare instances where they are [+Dlinked], they still convey non-presupposed information. Thus, a [+D-linked] NIF consistently fulfils the background by providing a value for the variable introduced by a wh-phrase (see also footnotes 6 and 9), whereas contrastive categories are [-presupposed] simply in virtue of being contrastive. That is, even when a contrastive interpretation is assigned to a discourse-anaphoric constituent, as in (19), it provides this constituent with the non-presupposed information that it must be construed as belonging to a pragmatic set of alternatives. This information is not previously known or taken for granted, so that the contrastive interpretation must itself be non-presupposed.

\subsection{The Distribution of Contrastive Categories ${ }^{22}$}

Since the above IS categories are [-presupposed], they are, arguably, subject to the generalization in (6) in Russian. However, as already mentioned, this generalization does not hold on the surface, as CF (including EF) and CT are typically fronted. ${ }^{23}$

What the hypothesis put forward here amounts to, then, is that the launching site for the movement of CF and CT is the position in which NIF must surface (Titov 2007, Neeleman \& Titov 2009). This follows if CF and CT are a composite of the features [-presupposed] and [+contrastive]. Movement of CF and CT would then be licensed by the positive value of the [ \pm contrastive] feature, but the launching site of that movement would be dictated by (13): ${ }^{24}$

$$
\begin{aligned}
& \text { Distribution of focused constituents in Russian (to be revised) } \\
& \text { i. } \quad\left[(\ldots)[\text {-presupposed; }- \text { contrastive }]_{\mathrm{NIF}}\right] \\
& \text { ii. }\left[(\ldots)[\text {-presupposed; +contrastive }]_{\mathrm{CF} / \mathrm{EF} 1} \ldots \ldots \ldots t_{1}\right] \\
& \text { iii. }\left[\left[(\ldots)[\text {-presupposed; +contrastive }]_{\mathrm{CT} 1}(\ldots) t_{1}[\text {-presupposed; -contrastive }]_{\mathrm{NIF}}\right]\right.
\end{aligned}
$$

Note that the focus in Top/Foc structures is analysed as [-contrastive] in (21iii). To recall, for a [-presupposed] constituent to be interpreted as contrastive, the set of alternatives must become active for it at the point the sentence that contains it is uttered. Yet, nothing in a Top/Foc utterance indicates that the focused constituent belongs to a pragmatic set of alternatives (see (1)-(4)). That is, such an utterance contains neither a link to a member of a set of alternatives to which the focused constituent also belongs or to a superset it is a member of, nor any overt markers of contrast. Moreover, an alternative member does not have to be mentioned in the following context either:

(22) [What did John eat at the bbq party?]CONTEXT

$[\text { Fred }]_{\mathrm{CT}}$ ate [beef burgers $]_{\mathrm{NIF}}$, and John is actually a vegetarian, so he didn't eat at all

[What did John eat at the bbq party?] CONTEXT 
$[\text { Fred }]_{\mathrm{CT}}$ ate $[\text { beef burgers }]_{\mathrm{NIF}}$,

and John might have actually eaten beef burgers as well

The hypothesis that the primary focus in Top/Foc structures is a NIF is further supported by two observations. First, in Russian, this focus is assigned IK1 - the accent reserved for NIF, rather than IK2, which marks CF. Second, in Russian, this focus remains in clause final position, whereas $\mathrm{CF}$ optionally undergoes A'-fronting. ${ }^{25}$

Indeed, it is the fact that the focus in Top/Foc structures is a NIF that accounts for the interpretation of incompleteness they are associated with. To be exact, a NIF can provide a focus value only for the proposition in the reply but not the one in the context. The contextual proposition is therefore left without a focus value, which subsequently triggers the interpretation of incompleteness. If the focus in Top/Foc structures were contrastive, the discourse would contain a salient set of at least two focus values: one for the proposition in the reply and one for the contextual proposition. In such a case, the interpretation of incompleteness linked to Top/Foc structures would be inaccessible, as the question in the context would receive an answer. In section 4 I show that this is indeed what happens in sentences like (5) that are traditionally taken to contain a $\mathrm{CF}^{26}$

The proposal advanced in this section contradicts the analysis advocated in Bolinger (1961) and Dretske (1972) that sees all foci as contrastive. Contrast is seen here as an extra interpretative property that can be added to a non-presupposed constituent and that licenses its A'-fronting. At the same time, it follows from the theory proposed here that only non-presupposed constituents can be contrastive, as contrastive interpretation is itself non-presupposed.

In section 2, it was demonstrated that an A-scrambled structure can serve as input to A'-movement of [+contrastive] constituents as long as A-scrambling is licensed by the rule in (13). To recall, the rule in (13) accounts for cases where a [+presupposed] object A-scrambles across a [-presupposed] subject, with the outcome that the former linearly precedes and outscopes the latter. Plausibly, such a scrambled structure can serve as input to A'-movement as long as the [-presupposed] subject is [+contrastive]. That is, if CF is analysed as a composite of the features [-presupposed] and [+contrastive], the former feature should determine its underlying position below a [+presupposed] argument in accordance with (13), whereas the latter feature should license its A'-movement. This hypothesis is indeed supported by the scopal properties of CFs, and in particular by the observation that they take scope in the same position as NIFs. The data fall out from (13), if A'-scrambling obligatorily reconstructs for scope.

Recall that Russian sentences with NIF have surface scope, as, in line with (13), quantifiers that constitute NIF scope under backgrounded quantifiers (see (10)). The pattern of surface scope breaks down in the case of CFs (see (24)). Though these are fronted, they reconstruct obligatorily to a position below backgrounded quantifiers. Thus, the fronted CF in (24b) takes scope in the same position as the NIF in (10b).

\begin{tabular}{lllll} 
(a) & $\left.\begin{array}{llll}\text { Každuju } & \text { otkrytku }\end{array}\right]_{\mathrm{CF} 1,}$ ja & xoču, čtoby \\
every & \multicolumn{1}{c}{ postcard-ACC } & I & want that \\
dva & studenta & podpisali & $t_{1}$, & (a ne každuju knigu) \\
two & students & signed & & (and not every book)
\end{tabular}

'I want two students to sign every postcard (not every book).'

(b) $[\text { Každyj student }]_{\mathrm{CF} 1}$, ja xoču, čtoby 


\begin{tabular}{llll} 
every & \multicolumn{1}{c}{ student } & I want & that \\
dve & otkrytki & podpisal $t_{1}$, & (a ne každyj docent) \\
two postcards-ACC & signed & (and not every lecturer) \\
'I want every student to sign two postcards (not every lecturer).'
\end{tabular}

$\exists>\forall ; * \forall>\exists$

It is not surprising that Russian contrastive foci can move. In a wide range of languages, contrastive elements undergo A'-movement. What is surprising is that the position into which contrastive foci reconstruct should be as low as it seems to be. That is, in an all-focus sentence, a subject outscopes an object in Russian because its position c-commands (and precedes) the object position. ${ }^{27}$ However, when subjects are fronted as contrastive foci, they scope under the object, suggesting that the fronting operation is launched from a position below the object. On the other hand, if the rule in (13) is taken into account, then a Russian [+presupposed] object is expected to A-scramble across a [-presupposed] subject, explaining the scopal properties of fronted foci. In other words, an A-scrambled structure, as in (10b), where a [+presupposed] object is interpreted as more prominent than a [-presupposed] subject in line with (13), serves as input to A'movement of the [-presupposed] subject when the latter is [+contrastive] (see (24b)).

CTs, conversely, have been shown to reconstruct above NIFs (see (14)), as this time the relative argument prominence is regulated by the [ $\pm \mathrm{D}$-linked] feature. Crucially, the generalization in (6) predicts that ALL [-presupposed] constituents, including CTs, must be interpreted in a clause final position, and must therefore take scope below [+presupposed] elements. This prediction is indeed borne out:

(25) (a) [When does Ivan want two teachers to visit every lecturer?]CONTEXT RU [Každogo studenta $]_{\mathrm{CT} 1}$, Ivan xočet, čtoby dva učitelja every student-ACC Ivan wants that two teachers posetili $t_{1} \quad$ [v subbotu $]_{F O C} \quad$ (a nasčët každogo docenta ne znaju) visited on Saturday (and about every lecturer not know) 'As for every student, Ivan wants two teachers to visit him on Saturday (but I don't know about every lecturer).' $\quad \exists>\forall ; * \forall>\exists$

(b) [When does Ivan want every lecturer to visit two teachers?]CONTEXT [Každyj student] $]_{\mathrm{CT} 1}$, Ivan xočet, čtoby dvux učitelej every student Ivan wants that two teachers-ACC posetil $t_{1} \quad$ [v subbotu]FOC (a nasčët každogo docenta ne znaju) visited on Saturday (and about every lecturer not know) 'As for every student, Ivan wants him to visit two teachers on Saturday (but I don't know about every lecturer).' $\quad \exists>\forall ; * \forall>\exists$

The observation that CTs reconstruct below backgrounded arguments but above NIFs is captured by (13), which interprets a [+presupposed] argument as more prominent than a [-presupposed] argument and a [-presupposed; +D-linked] argument as more prominent than a [-presupposed; -D-linked] argument.

The reconstruction facts in (14), (24) and (25) can be summarized as follows. Within the standard approach to Russian syntax, an unmarked monotransitive construction has the [IP $\mathrm{S}_{1}$ [VP $\left(t_{1}\right)$ [V O]]] structure. An A-scrambled structure created either through A-movement or base-generation has to capture the fact that, on the surface, an A-scrambled object precedes an auxiliary verb generated in the I-node, such as the 
modal moč 'can', suggesting that this object moves out of the VP to SpecIP either from object position or from an A-scrambled position above the subject, depending on one's approach to A-scrambling. Since the base-generation analysis accounts for the surface position of the verb without the introduction of an additional projection and captures the surface scope facts without further stipulations, it will be used here for presentational convenience, with the outcome that an A-scrambled monotransitive sentence will be taken to have the [IP $\mathrm{O}_{1}$ [VP $\left.\left.t_{1}[\mathrm{~V} \mathrm{~S}]\right]\right]$ structure. ${ }^{28}$ Thus, whenever A-scrambling is licensed by the [ \pm presupposed] feature, the [IP $\mathrm{O}$ [vp $\left.t_{1}\left[\mathrm{~V} \mathrm{~S} \mathrm{~S}_{\mathrm{NIF}}\right]\right]$ surface structure is created (see (10)), with the [+presupposed] object outscoping the [-presupposed] subject. This structure serves as input for the [ $\mathrm{CP}_{\mathrm{CF} 2}\left[\mathrm{IP} \mathrm{O}_{1}\left[\mathrm{VP} t_{1}\left[\mathrm{~V} t_{2}\right]\right]\right]$ construction where the focus is contrastive and A'-moves but reconstructs to the position of its trace, with the scope readings matching the input A-scrambled structure (see (24b)). The [ \pm presupposed] feature can also license the [IP O [vp[vp $\left.\left.\left.t_{1}\left[\mathrm{~V} \mathrm{~S} \mathrm{~S}_{\mathrm{CT}}\right]\right] \mathrm{Adj}_{\mathrm{NIF}}\right]\right]$ structure, which additionally contains a focused adjunct. This structure serves as input to the [CP $\mathrm{S}_{\mathrm{CT} 2}$ [IP $\mathrm{O}$ [vp[vp $t_{1}$ [V $t_{2}$ ]] AdjNIF]]] structure where the [-presupposed] subject A'-moves but reconstructs to the position of the trace below the [+presupposed] object (see (25b)). Finally, when Ascrambling is licensed by the [ $\pm \mathrm{D}$-linked] feature, the [IP $\mathrm{O}_{\mathrm{CT}}\left[\mathrm{vP} t_{1}\left[\mathrm{~V} \mathrm{~S}_{\mathrm{NIF}}\right]\right]$ structure results. This structure is input to the [CP $\mathrm{O}_{\mathrm{CT} 1}$ [IP $t_{1}$ [vP $t_{1}$ [V S SIF]]]] structure, as in (14), which exhibits surface scope.

The Russian data have been presented in terms of the features [ \pm presupposed], $[ \pm \mathrm{D}$ linked] and [ \pm contrastive] because they support a decompositional view of CF and CT. In order to explain why $\mathrm{CF}, \mathrm{CT}$ and NIF share an underlying position, we must assume that they share some attribute, namely the negative value of the [ \pm presupposed] feature, with the [ $\pm \mathrm{D}$-linked] feature regulating the underlying position of the $\mathrm{CT}$ with respect to NIF. In order to explain why only CF and CT move, we must assume that they have an additional property that new information foci lack, that is, the positive value as regards the $[ \pm$ contrastive] feature.

\section{CONTRASTIVE TOPIC VERSUS CONTRASTIVE Focus}

So far we have established that both CF and CT are associated with the features [-presupposed] and [+contrastive], with the former feature accounting for their underlying clause final position, and the latter licensing their A'-fronting in Russian. The fact that CTs and CFs are characterized by identical interpretative features and exhibit identical syntactic behaviour suggests that they represent one and the same IS notion. Yet, the sentences that host them have quite distinct interpretations. Recall that sentences with a $\mathrm{CF}$ have the interpretation of counter-assertion to a proposition in the context, whereas sentences that host a CT have the interpretation of incompleteness. Consequently, the latter can occur in a context that is incompatible with the former, namely, when the discourse antecedent generalizes over the set to which the nonpresupposed constituent belongs (see (26) versus (27)).

(26) [What do your students work on?]CONTEXT

Well, [Mary $]_{\mathrm{CT}}$ works on [Icelandic $]_{\mathrm{NIF}}$, (and John on Russian)...

(27) [Did you feed the animals? $]_{\text {CONTEXT }}$

\# No, I fed [the cat $]_{\mathrm{CF}}$ (not the animals) 
In (27), I fed the cat fails to stand in opposition to I fed the animals as the latter entails the former as long as the cat is construed as belonging to the set of animals. ${ }^{29}$

A further difference between the structures that contain CF and CT is that in the former the $\mathrm{CF}$ seems to be the only [-presupposed] constituent in the sentence, whereas in the latter there is always an additional [-presupposed] element present in the sentence, namely a NIF. Moreover, constituents interpreted as CT and those conveying the interpretation of $\mathrm{CF}$ receive distinct intonational contours. That is, a $\mathrm{CF}$ is marked with a falling contour, whereas a CT receives a (fall)-rise intonation.

However, Molnár (2002) argues on the basis of examples like (28) that NIF (Molnár's INFORMATION FOCUS) can also be marked with a (fall)-rise intonation, suggesting that this intonational contour is not exclusive to CTs.

(28) [Did you feed the animals?] CONTEXT

I fed [the cat]

Molnár (2002)

However, three observations undermine the analysis of the object in (28) as NIF. First, this object is contrastive, as it is the introduction of the cat into the discourse that activates the construal of the animals as generalizing over a set of animals, of which the cat is a member. ${ }^{30}$ Second, this object cannot be analysed as what is traditionally called focus. Even if the contrastive interpretation is taken into account, an analysis of the object as a CF fails because its antecedent generalizes over the set that the object belongs to. As shown in (27), such a context is incompatible with the interpretation conveyed by sentences hosting a CF, strongly suggesting that the [-presupposed] object in (28) is not a CF but in fact a CT. The final potential obstacle to analysing the object in (28) as a CT is the fact that this object seems to be the only [-presupposed] element in the sentence, whereas Top/Foc structures have been shown to additionally contain a NIF. However, a careful examination of the IS of the sentence in (28) reveals that it does indeed contain an additional [-presupposed] element. To be exact, the question in the context in (28) is a yes/no-question, which by default requests information about the truth-value of a proposition. Consequently, any answer to such a question must contain focus on the truthvalue of the proposition or VERUM FOCUS (henceforth VF). This type of focus is, as a rule, marked on the inflection:

(29) [Did you feed the animals?] CONTEXT

Yes, I [did $]_{\mathrm{NIF}}$ (feed the animals)

The sentence in (29) occurs in the same context as that in (28), but here the VF is the only [-presupposed] element and hence the only element that can carry main stress. In (28), by contrast, the [-presupposed] object can be prosodically marked. It would seem, then, that English has the option of not marking VF in sentences of the latter type. It is, however, possible to keep the prosodic marker on the inflection in (28), as in (30).

(30) [Did you feed the animals?]

I $[\text { did }]_{\mathrm{NIF}}$ feed $[\text { the cat }]_{\mathrm{CT}}$

Interestingly, the option of not marking VF in such sentences appears to be an example of parametric variation, as other languages, like, for instance, Russian, must 
contain a prosodic marker on the inflection even in the presence of an additional prosodically marked [-presupposed] element (see (31)).

(31) [Did you feed the animals? $]_{\text {CONTEXT }}$

RU
$[\text { Kota }]_{\mathrm{CT}}$ ja
$[\text { pokormil }]_{\mathrm{NIF}}$
cat-ACC I fed-PAST.MASC.SG
'As for the cat, I fed it...'

The concept of VF demands a reanalysis of sentences hosting CF as these most naturally occur in the context of a yes/no-question and hence must also contain VF. In fact, sentences with $\mathrm{CF}$ and those hosting CT quite naturally occur in the same context:

[Did John buy a Volkswagen?] CONTEXT

(a) (No), John bought [a Toyota $]_{\mathrm{CF}}$, (not a Volkswagen)

(b) John bought [a Toyota] $]_{\mathrm{CT}}$, (but I don't know about a Volkswagen)

[Did Ivan buy a Volkswagen?]CONTEXT

(a) (Net), Ivan [Toyotu $]_{\mathrm{CF}}$ kupil, (a ne Volkswagen)

(No) Ivan Toyota-ACC bought (and not Volkswagen)

'No Ivan bought a Toyota (not a Volkswagen).'

(b) $[\text { Toyotu }]_{\mathrm{CT}}$ Ivan [kupil $]_{\mathrm{NIF}}$, (a nasčët Volkswagena ja ne znaju)

Toyota-ACC Ivan bought (and about Volkswagen I not know)

'Ivan bought a Toyota, (but I don't know about a Volkswagen).'

It is not surprising that a sentence hosting a $\mathrm{CF}$ and one containing a $\mathrm{CT}$ occur in the same context in (32) and (33), as sentences with distinct information structures are often compatible with identical contexts. ${ }^{31}$ Then again, the (a) and the (b) sentences in (32) and (33) both contain a [-presupposed; +contrastive] object and a VF. So, what exactly is distinct in the IS of the (a) vs. (b)-sentences in (32) and (33) and responsible for the difference in their interpretation (i.e. opposition vs. incompleteness)?

By hypothesis, the main interpretative difference between the (a)-sentences and the (b)-sentences in (32) and (33) is due to a distinct value as regards the [ \pm contrastive] feature carried by the VF. That is, the sentences hosting a CT as in (32b) and (33b) contain a [-contrastive] VF, whereas in (32a) and (33a) the VF is [+contrastive]. ${ }^{32}$

The fact that VF is non-contrastive in the (b)-sentences is expected, because the additional [-presupposed] element in sentences hosting a CT is a NIF. To recall, a noncontrastive focus can only provide a focus value to one proposition and, in accordance with this observation, the VF in the (b)-sentences in (32) and (33) only provides a truthvalue for the proposition in the reply but not for the one introduced in the context. The contextual proposition is left without a focus value, giving rise to the interpretational effect of incompleteness typical of Top/Foc structures.

The VF in the (a)-sentences, conversely, does not only provide a truth-value for the proposition in the reply but also treats the proposition in the context as having an alternative truth-value. As a result, the interpretation of belonging to a set of alternatives becomes active for the VF in the (a)-sentences at the point these sentences are produced, strongly suggesting that this focus is indeed contrastive. As the set of truth-values is a closed set with only two members, when VF is contrastive, the alternative truth-value to the one given to the proposition in the reply is always the opposite one, which accounts for the interpretation of opposition conveyed by sentences hosting a contrastive VF. 
As is the case with non-contrastive VF, contrastive VF is prosodically marked on an inflection whenever there are no other [-presupposed] elements in the sentence:

[John bought a Volkswagen] $]_{\text {CONTEXT }}$

(No), he didn't (buy a Volkswagen).

However, in sentences that additionally contain a [-presupposed] constituent, as in (32a) and (33a), a contrastive VF is not overtly marked. It appears that the option of prosodic marking of VF in this type of sentence is reserved for NON-CONTRASTIVE VF found in Top/Foc structures. The selective nature of prosodic marking of VF might be a result of a blocking effect at the interface between PF and IS. Assuming that structures with distinct interpretations must be disambiguated either via prosody or/and context, assigning a particular prosodic pattern to a structure with a particular interpretation is expected to block the association of this pattern with a distinct interpretation within the same context. Hence, in a context that licenses either a Top/Foc structure or a structure with a CF, as in (32) and (33), a marked VF is construed as [-contrastive], whereas for the contrastive interpretation, VF is not allowed to be prosodically realized. ${ }^{33}$

Conversely, whenever the opposite truth-value for a contrastive VF is not merely implied but overtly present in the context, this focus can no longer be interpreted as noncontrastive. In such a case, the interpretation reserved for Top/Foc structures is unattainable and therefore no longer blocks the one conveyed by sentences hosting a CF. As expected, a [+contrastive] VF can be prosodically marked in such a context:

(35) A: [Did John buy a Volkswagen?]CONTEXT

B: No, John didn't buy a Volkswagen but John did buy [a Toyota $]_{C F}$

The discourse in (35) is interpretatively identical to the one in (32a), but in the former, both truth-values are overtly realized. Consequently, the VF is unambiguously contrastive in (35) and is therefore allowed to be prosodically realized.

The blocking effect related to prosodic marking of VF can be captured by the Elsewhere Condition (cf. Anderson 1969, Kiparsky 1973), which states that application of a general rule is blocked where a more specific rule can be applied. By hypothesis, the relevant rules apply at the interface between PF and IS. Assuming that the general rule states that a PF representation with a prosodic marker on the inflection is chosen for an IS with VF, while the more specific rule maintains that such a PF is used for an IS with a [-contrastive] $\mathrm{VF}$, it is expected that whenever the [-contrastive] construal is contextually available, a PF with no prosodic marker on $\mathrm{I}^{\circ}$ must be used for the [+contrastive] reading. Conversely, when the non-contrastive interpretation cannot be attained due to the presence of an alternative truth-value in the context, a PF with a prosodically marked inflection is used for an IS with a [+contrastive] VF.

The fact that the alternative truth-value in (32a) is implied but not realized can be accounted for by stipulating that the part that contains it undergoes a deletion operation, as in (36), where the part in angled brackets is not pronounced.

[Did John buy a Volkswagen?] CONTEXT $\left(\right.$ No) $<$ John didn't buy a Volkswagen $>$, John bought $[\text { a Toyota }]_{\mathrm{CF}}$ 
The analysis in (36) implies that the [+contrastive] VF fails to be prosodically marked because the alternative truth-value is not pronounced, hence, the more specific rule applies and blocks the application of the general rule.

What remains to be explained is why it is possible to answer a question that asks for the truth-value of the proposition John bought a Volkswagen by providing a value for an alternative proposition, namely, John bought a Toyota. I would like to argue that this is due to the reply in (32a) treating the question in the context as a subquestion dominated by the question under discussion What car did John buy?, with other subquestions, such as Did John buy a Toyota? remaining implicit:

Sentence containing CF and [+contrastive] VF

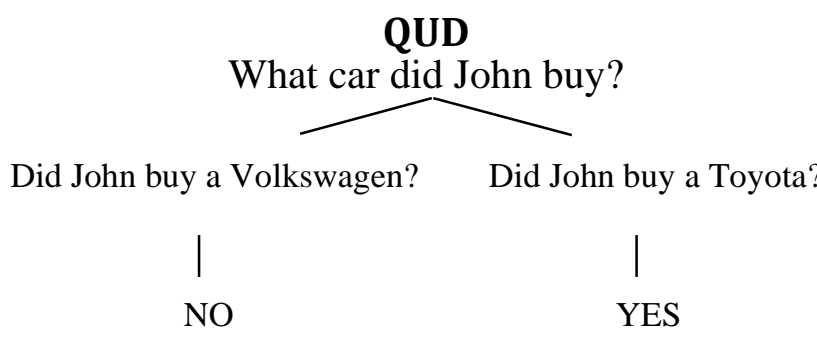

The hypothesis that sentences hosting a $\mathrm{CF}$ contain an answer to an implicit question goes hand in hand with the analysis of Top/Foc structures proposed by Büring (2003). Following Büring's theory of DisCOURSE-TREES, the Top/Foc structure in (32b) can be analysed as occurring in a context where a QUESTION UNDER DISCUSSION (henceforth QUD) dominates two subquestions: an explicit question given in the context and an implicit question that is provided with an answer by the reply (see (38)). As the $\mathrm{VF}$ in (32b) is [-contrastive], it fails to provide the explicit subquestion with an answer, which results in the interpretation of incompleteness.

Sentence containing CT and [-contrastive] VF

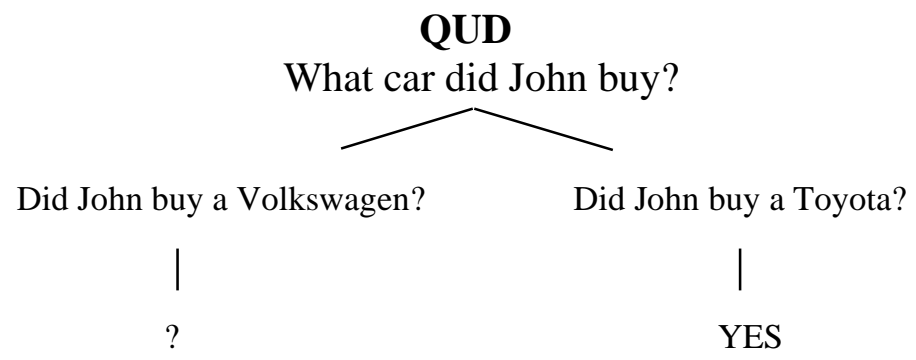

Since the sentence in (32a) occurs in the same context as the one in (32b), it is plausible that they have the same QUD that dominates two subquestions, an explicit and an implicit one (see (37)). However, as the VF is contrastive in (32a), both subquestions dominated by the QUD, including the explicit question in the context, receive an answer (see (37)). No questions are left unanswered; hence, no interpretation of incompleteness arises. Instead, the interpretation of opposition results from the proposition in the context and the one in the reply having opposite truth-values. 
Importantly, the interpretive difference between (32a), hosting a $\mathrm{CF}$, and (32b), containing a $\mathrm{CT}$, comes down to the nature of the $\mathrm{VF}$, or more precisely, to its value with respect to the [ \pm contrastive] feature, and not to any particular difference between the CF and CT per se. This outcome quite naturally captures the observation that a sentence hosting a CF cannot occur in a context where the focus is linked to a superset, as in (27). In (27), the reply provides a positive answer to a subquestion but fails to offer a negative answer to the superquestion in the context, as some subquestions remain unanswered (see (39)). Since the alternative truth-value cannot be given to the proposition in the context, VF fails to be construed as contrastive. ${ }^{34,35}$

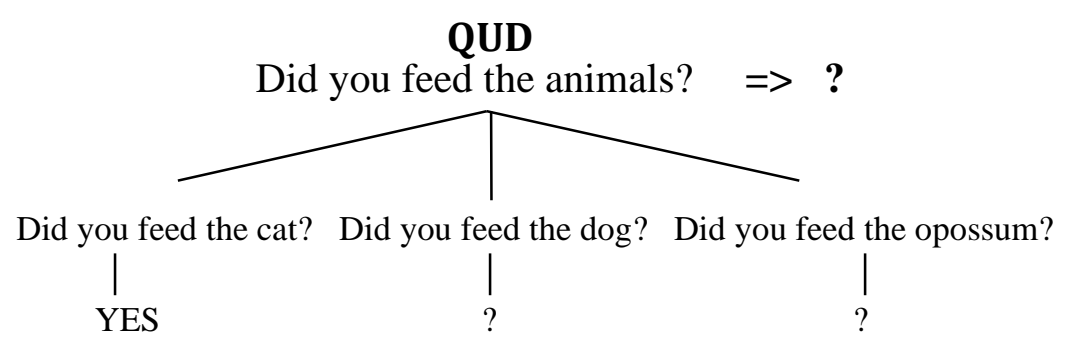

The above analysis implies that Top/Foc structures are in fact CF/NIF structures, where the interpretation of NIF can be expressed either on an inflection (VF) or on an $\mathrm{XP}$; whereas sentences hosting what is traditionally referred to as $\mathrm{CF}$ always contain a CONTRASTIVE VERUM Focus (henceforth CVF): ${ }^{36}$
Constructions hosting [-presupposed; + contrastive] XPs
a. $\mathrm{CT} / \mathrm{FOC}=>\mathrm{CF} / \mathrm{NIF}$
b. $\ldots \mathrm{CF} \ldots \Rightarrow \mathrm{CF} / \mathrm{CVF}$

As suggested in (40), CT and CF represent one and the same IS category that can occur in two different types of constructions. The fact that the structures in (40) have distinct interpretation accounts for the difference in intonational contours assigned to the CFs in them. Yet, English and Russian have different reasons for the distinct prosodic marking.

In English, the blocking effect at the interface between PF and IS ensures that the interpretation assigned to a prosodically marked VF in an ambiguous context is noncontrastive, with the consequence that the relevant sentence has the CF/NIF and not CFCVF structure. However, prosodic marking of the [-contrastive] VF is optional in this language and can be omitted (see (28)). As a result, a structure with a prosodically unrealized VF and a CF is ambiguous in interpretation and can be disambiguated only by assigning distinct contours to the $\mathrm{CFs}$, i.e. the $\mathrm{B}$-accent, to achieve the interpretation in (40a) and the A-accent for the reading in (40b), as in (32b) and (32a) respectively. ${ }^{37}$

In Russian, on the other hand, the reason for marking CF in a structure like (40a) with a rising contour IK3 is of a much simpler nature. Russian is a language that does not permit more than one falling intonational contour in one clause. At the same time, the [-contrastive] focus must always be marked with IK1, even a [-contrastive] VF (see (31)). Consequently, whenever CF co-occurs with a NIF, it can no longer be marked with a falling contour. At the same time, $\mathrm{CF}$ is [-presupposed] and must carry a prominent prosodic marker. This leaves a rising contour the only available option. 
As shown in (41), the notion of CT is not needed to account for the distribution of [-presupposed] constituents in Russian and can be easily reduced to that of CF. ${ }^{38}$

$$
\begin{aligned}
& \text { Distribution of [-presupposed] elements in Russian } \\
& \text { NIF } \\
& \text { i. } \quad[\mathrm{CP}(\ldots)[- \text { presupposed; }- \text { contrastive }]]^{39} \\
& \mathrm{CF} \quad \mathrm{CVF}
\end{aligned}
$$

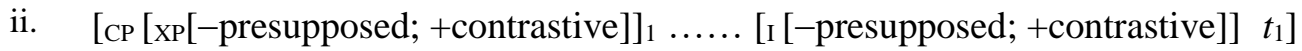

$$
\begin{aligned}
& \mathrm{CF} \\
& \text { iii. [СР [ХР [-presupposed; +contrastive } \left.]]_{1} \ldots \ldots . . t_{1}[\mathrm{XP}[- \text { presupposed; }- \text { contrastive }]]\right]
\end{aligned}
$$

A CF can be then said to have the following properties:

1. It is associated with the [+contrastive] feature, which licenses its A'-fronting;

2. It is associated with the [-presupposed] feature, which forces its reconstruction to the position where non-contrastive focus surfaces;

3. It can co-occur with a [-presupposed; -contrastive] element, which results in the interpretation of incompleteness conveyed by the sentence that hosts the $\mathrm{CF}$ and a (fall)rise intonation assigned to the $\mathrm{CF}$;

4. It can co-occur with a [-presupposed; +contrastive] VF, which results in the interpretation of counter-assertion conveyed by the sentence that hosts the $\mathrm{CF}$ and a falling intonation assigned to the $\mathrm{CF}$.

The next section looks at the interaction of focus sensitive operators with $\mathrm{CF}$, showing why certain operators are incompatible with the interpretation of incompleteness.

\section{DISCOURSE STRATEGIES}

\subsection{Interpretation of CF/NIF (TOP/FOC) sentences}

It has been observed by various linguists that certain focus sensitive operators are incompatible with the interpretation of what is traditionally called CT (see (42)). On the other hand, CFs can be associated with these quantifiers (see (43)). This appears to undermine the analysis proposed in the present paper that sees CTs as identical to CFs.

[Did you feed the cat?] CONTEXT

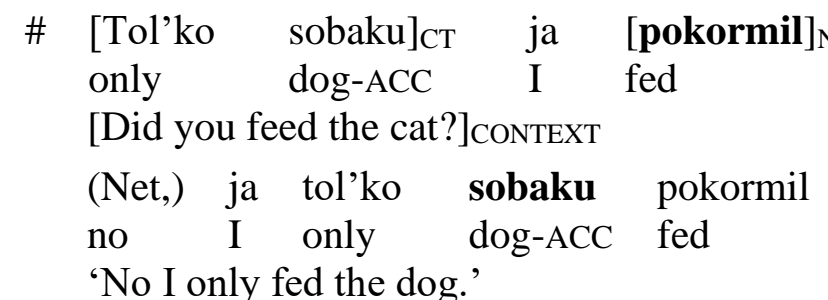

However, I will demonstrate on the basis of a variety of discourse strategies that it is not the CT that is incompatible with focus sensitive operators but rather the interpretation of incompleteness, which fails to be achieved when the operators are applied to the structure. 
Moreover, I will show that the interpretation of counter-assertion conveyed by structures hosting CF also often clashes with the semantics of focus sensitive operators.

To recall, the focus in Top/Foc structures is NIF that can only provide a focus value for one (newly introduced) proposition. As a result, the proposition that is already present in the context is not given any focus value and can therefore be understood as either having the same focus value as the newly introduced proposition (see (23)) or a different focus value (see (22)). Crucially, once the contextual proposition obtains a focus value, the interpretation of incompleteness becomes unavailable. ${ }^{40}$

(44) gives the discourse interpretation conveyed by Top/Foc sentences.

\section{(44) Interpretation of TOP/FOC (or CF/NIF) structures}

Let's say there is a set of entities $\langle a, b\rangle$ and a set of properties $\langle\mathrm{p} 1$, p2 $\rangle$ :

[What property holds of $a$ ?] CONTEXT

Interpretations that are compatible

$[\mathrm{p} 1]_{\mathrm{NIF}}$ holds of $[b]_{\mathrm{CT}} \quad \Rightarrow \quad$ p1 holds of $a$ (see (23))

p2 holds of $a$ (see (22))

The context introduces the entity $a$, and requests information about the property that holds of $a$. The Top/Foc sentence in the reply, however, fails to provide this information. Instead, it provides information about the property that holds of a newly introduced entity $b$. As the discourse does not establish what property holds of $a$, it can be interpreted as either having the same property as $b$ or as having a different property.

To formally represent the interpretation conveyed by a sentence hosting a CT, it is necessary to capture the intuition that the proposition in the context does not have a focus value ONLY within the speaker's beliefs. Plausibly, discourse-related categories such as $\mathrm{CT}$ and CF can only be nested in a discourse where interlocutors exchange their (possibly contradicting) beliefs. Therefore, a sentence with either a CT or a CF contains information relevant for the epistemic state of the speaker rather than the facts about the world. Thus, a sentence hosting a CT conveys that the speaker does not know whether the contextual proposition has the same or a distinct focus value as the newly introduced proposition, whereas a sentence with a CF expresses the speaker's belief that the contextual proposition has a distinct focus value to the newly introduced proposition.

One way to represent the interpretation of sentences containing a CT or a $\mathrm{CF}$ is to define belief as a kind of quantification over worlds. ${ }^{41}$ Following Heim (1992), I adopt the notion of doxastically accessible worlds. If we assume a function "dox" that takes an individual as an argument and returns the set of all possible worlds that are compatible with his/her beliefs, we get the following possible interpretations for sentences with VF:

1. If the speaker $s$ believes a proposition introduced in the context is true, then for all worlds $w$ in $\operatorname{Dox}(s)$, this proposition is true in $w$.

2. If the speaker believes a contextual proposition is false, then for all worlds $w$ in $\operatorname{Dox}(s)$, the negation of this proposition is true in $w$.

3. If the speaker does not know whether or not the proposition introduced in the context is true, then there is a world $w$ in $\operatorname{Dox}(s)$ such that this proposition is true in $w$, and another world $w^{\prime}$ in $\operatorname{Dox}(s)$ such that the negation of this proposition is true in $w^{\prime}$.

The sentences in (45) illustrate these interpretative possibilities.

[Did John buy a Volkswagen?] CONTEXT 
(a) (Yes), John did (buy a Volkswagen)

(b) (No), John bought [a Toyota $]_{\mathrm{CF}}$ (not a Volkswagen)

(c) John bought [a Toyota]ct (but I don't know about a Volkswagen)

The interpretation of a sentence that hosts a CF, as in (45b), is such that it includes a negation of the proposition introduced in the context for all worlds $w$ in Dox $(s)$, whereas the interpretation of a sentence containing a CT, as in (45c), implies that there is a world $w$ in $\operatorname{Dox}(s)$ such that this proposition is true in $w$, and another world $w^{\prime}$ in $\operatorname{Dox}(s)$ such that the negation of this proposition is true in $w^{\prime}$.

Since CT and CF are claimed here to be one and the same IS notion, it is expected that both have focus semantics. I will adopt a notational variant of focus representation (from Neeleman \& Vermeulen, forthcoming), which represents the focus, as well as the set of alternatives to the focus found in the alternative propositions:

$$
\langle\lambda x[\text { John bought } x] \text {, Toyota, }\{\text { Toyota, Volkswagen, Bentley, ... }\}>
$$

In (46), the ordinary value of the sentence is generated by applying the function (corresponding to the background in $(45 b, c)$ ) to the focus, while the focus value is generated by applying it to members of the set of alternatives.

Previously, we have argued that focus can be additionally supplemented with contrastive interpretation, which is the case with CF, CT and EF. The definition of contrast proposed here suggests that contrast involves quantification over a set of discourse relevant entities $\{a, b, c, \ldots\}$. After all, for an element to be construed as contrastive, the interpretation of belonging to a pragmatic set of alternatives must be activated by the sentence that contains this element. Thus, in (45b, c), contrast expresses to what extent the set of (contextually relevant) cars is contained in the set of things that John bought. The interpretation of both sentences entails that, according to the speaker's beliefs, one element of the set of cars is also an element of the set of things that John bought. The sentence with a CF in (45b) additionally expresses the speaker's belief that the other contextually relevant member of the set of cars (i.e. a Volkswagen) is not contained in the set of things that John bought. The sentence with a CT in (45c), in contrast, expresses that the speaker does not know if the other contextually relevant member of the set of cars is contained in the set of things that John bought or not.

Therefore, the interpretation of sentences hosting CF or CT additionally requires quantification over the set of worlds within the speaker's beliefs. Hence, such sentences involve two types of quantification: quantification over a set of contextually salient entities $\{a, b\}$ that can provide a value for $x$ in John bought $x$; and quantification over doxastically accessible worlds $\left\{w, w^{\prime}\right\}$ that allow for John bought a and/or for John bought $b$. Assuming that the discourse that nests the sentences with a CF or a CT is compatible with the context where the speaker receives an instruction to express their beliefs as to to what extent the set of (contextually relevant) cars is contained in the set of things that John bought, the following discourse representation arises:

Instructions compatible with the context

Out of the alternative entities $\{a, b\}$, in how many doxastically accessible worlds $(\operatorname{Dox}(s))$ does $a$ fulfil the background $\mathrm{B}$ and turn it into a true proposition? 
in how many doxastically accessible worlds $(\operatorname{Dox}(s))$ does $b$ fulfil the background B and turn it into a true proposition?

Interpretation of a sentence with a $C F$

$a$ fulfils B in all worlds in (Dox $(s)), b$ fulfils B in no worlds in (Dox $(s))$.

Interpretation of a sentence with a $C T$

$a$ fulfils B in all worlds in (Dox $(s)), b$ fulfils B in $w$ and $b$ does not fulfil B in $w$ '.

The fact that $a$ fulfils B is already part of the simple focus representation given in (46). What is specific for the semantics of sentences hosting a CF or a CT is that there is another contextually relevant entity that can fulfil B in some doxastically accessible worlds but not in others: ${ }^{42}$

(50) Semantics of sentences hosting a $C F$

(a) $\langle\lambda x$ [John bought $x$ ], Toyota, \{Toyota, Volkswagen, Bentley, ... $\}\rangle$

(b) $\exists x[x \in\{$ Toyota, Volkswagen, Bentley, ... \& \& $x \neq$ Toyota $\& \forall w[w \in \operatorname{Dox}(s)$ $\neg[$ John bought $x]]]$.

(51) Semantics of sentences hosting a CT

(a) $[\langle\lambda x[$ John bought $x]$, Toyota, $\{$ Toyota, Volkswagen, Bentley, ... $\}>$

(b) $\exists x[x \in\{$ Toyota, Volkswagen, Bentley, ... $\& x \neq$ Toyota $\& \exists w[w \in \operatorname{Dox}(s)$ $\&$ [John bought $x]] \& \exists w^{\prime}\left[w^{\prime} \in \operatorname{Dox}(s) \& \neg[\right.$ John bought $\left.\left.x]\right]\right]{ }^{43}$

The notation in (50b) must be read as follows: exists an entity that is an element of the same set that includes the focus but is not the same entity as the focus and for every world that is an element of a set of doxastically accessible worlds it is not true that John bought this entity. The notation in (51b), in contrast, states that exists an entity that is an element of the same set that includes the focus but is not the same entity as the focus and there exists a world $w$ that is an element of a set of doxastically accessible worlds in which it is true that John bought this entity and there exists a world $w^{\prime}$ that is an element of a set of doxastically accessible worlds in which it is not true that John bought this entity. Hence, both the positive and the negative truth-value of the proposition John bought a Volkswagen are compatible with an agent's beliefs in (45c), (49) and (51b).

The next subsection argues that focus sensitive operators alter the semantics of sentences by forcing a specific quantification over sets that is often incompatible with the quantification involved in the semantics of sentences hosting a $\mathrm{CT}$ or a $\mathrm{CF}$.

\subsection{Incompatibility with focus sensitive operators}

Before starting the discussion of the semantics of sentences affected by focus sensitive operators, such as the delimiting operator only or expanding operators including negative and universal quantifiers, it is vital to establish whether such operators can be included into the interpretation of narrow focus assigned to a constituent. ${ }^{44}$ That is, for a constituent that includes such an operator to be interpreted either as a CF or a CT, it is necessary for this constituent to allow the interpretation of narrow focus.

To recall, the semantics of focus involves selection out of a set of alternatives. For non-contrastive focus, this set is not pragmatically restricted, whereas for CF and CT, alternative member(s) must be active in the discourse. It is therefore expected that whenever the semantics of a focus sensitive operator involves a particular type of quantification over a set that is incompatible with the interpretation that sees the 
constituent that includes this operator as belonging to a set of alternatives, this constituent cannot carry narrow focus. For instance, in (52), the constituent a Toyota modified by the delimiting operator only is chosen out of a set of cars as the one that can provide a value for the variable in John bought $x$ and turn it into a true proposition. The delimiting operator adds an interpretation to this sentence that no other element of the set of cars is included into the set of things that John bought. Notably, only a Toyota cannot be the narrow focus of the sentence when the delimiting effect of the operator is active, as this constituent cannot be interpreted as a member of a set of cars (see (53)).

(52) [What car did John buy?]CONTEXT John only bought [a Toyota $]_{\text {FOC. }}$ $*<\lambda x[$ John bought $x]$, only Toyota, $\{$ only Toyota, Volkswagen, Bentley, ... $\}>$

Although in (52) the delimiting operator cannot be construed as included in the constituent that receives narrow focus, it still adds new non-presupposed information to the sentence that for every member of the set of cars except Toyota it is not true that John bought it. In other words, it adds the interpretation about the truth-value of alternative propositions. To recall, information about a truth-value of a proposition is expressed by VF. Since the delimiting operator in (52) activates the interpretation that there are alternative propositions relevant for the discourse at hand that have an alternative truthvalue to the proposition in the reply, this operator must be analysed as adding a contrastive VF to the sentence that already has focus on the object, i.e. it is a type of a MARKER OF CONTRAST on VF. As a result of the application of this marker of contrast, the sentence in (52) has CF on the object and a CVF. ${ }^{45}$

Similarly, a negative quantifier or a universal quantifier cannot be included in a set of cars in (54) and (55) because their semantics involves generalization over a set of alternatives, rather than selection out of such a set (see (56) and (57), respectively. ${ }^{46}$

(54) [What car did John buy?]CONTEXT

John bought no car.

(55) [What car did John buy?] CONTEXT

John bought every car.

$*<\lambda x[$ John bought $\mathrm{x}]$, no car, $\{$ no car, Volkswagen, Bentley, $\ldots\}>$
$*<\lambda x[$ John bought $\mathrm{x}]$, every car, $\{$ every car, Volkswagen, Bentley, $\ldots\}>$

Since the negative quantifier and the universal quantifier generalize over a set of cars in (54) and (55), it is impossible to construe the constituent that includes such a quantifier as belonging to a set of alternatives. As a result, no car and every car cannot be assigned narrow focus (see (56) and (57)).

Crucially, the replies in (54) and (55) do not directly answer the contextual question by selecting an entity out of a set of cars and stating that this entity belongs to the set of things that John bought. Instead, they either challenge or confirm the validity of the proposition John bought a car by assigning the value true or false to it. In other words, the sentences in (54) and (55) also contain VF. In (54), the VF is contrastive, as the sentence rejects the presupposition that John bought a car. Hence, both truth-values are active in the discourse in (54). In (55), in contrast, the VF is non-contrastive, as it confirms that the contextual proposition has the value true. 
However, assigning a truth-value to the contextual proposition is only part of the semantics of the sentences affected by expanding focus operators, as these additionally provide the interpretation, according to which, John bought $x$ is either false or true for every $x$. In other words, (54) does not only convey that John bought a car is false, it additionally expresses that no member of the set of cars exists for which it is true. Similarly, the sentence in (55) does not only convey that John bought a car is true, it additionally expresses that no member of the set of cars exists for which it is false.

Therefore, the sentences affected by the focus sensitive operators above must be analysed as containing two types of quantification: quantification over a set of truthvalues and quantification over a set of contextually relevant entities, with the latter incompatible with the semantics involving selection out of a set of alternatives. Hence, these operators cannot be included in a constituent with the interpretation of narrow focus, unless the delimiting or the expanding effects are neutralized (see section 5.2.1). It is therefore expected that they cannot be either a CT or a CF.

On the other hand, sentences affected by these operators are often compatible with the interpretation of counter-assertion but not that of incompleteness, yielding the false impression that the grammaticality of the former but not the latter is due to a difference between CT and CF. The next subsections discuss the interpretative clashes between the semantics of sentences affected by focus sensitive operators and those containing CTs, showing that these are not due to a difference between $\mathrm{CT}$ and $\mathrm{CF}$.

\subsubsection{Incompatibility with the delimiting focus operator 'only'}

A discourse strategy that makes use of only to modify a [-presupposed; +contrastive] constituent results in a positive answer to an implicit subquestion and a negative answer to the subquestion in the context and ALL the other potential subquestions (see (58a) and (59)). No subquestions are left unanswered; hence, no interpretation of incompleteness is available (see (58b)).

Conversely, the interpretation of counter-assertion conveyed by sentences containing a contrastive $\mathrm{VF}$, as in (58a), is compatible with such a strategy because the proposition John only fed the dog does stand in opposition to John fed the cat. Consequently, the proposition in the context and the one in the reply have opposite truthvalues and the VF is indeed contrastive in the reply.

(a) No, John only fed the dog.

(b) \# John only fed the dog (but I don't know if John fed the cat).

Did John feed the animals?<smiles></smiles>

Did John feed the cat? Did John feed the dog?

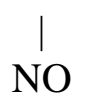

Did John feed the horse?

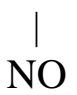

Assuming that the interpretation added by the delimiting operator to the semantics of a sentence with a simple focus, as in (60a), is the one given in (60b), it is expected to be compatible with the speaker's beliefs given in (50) but not (51), as the latter requires that there exists an entity that is an element of the set of animals but is not the same entity 
as the focus and that there exists a world $w$ within $(\operatorname{Dox}(s))$ where it is true that John fed this entity.

(60) (a) $<\lambda x[$ John fed $x]$, a dog, $\{$ a cat, a dog, a horse ... $\}>$

(b) $\forall x[x \in\{$ a cat, a dog, a horse... $\} \& x \neq$ a dog $\neg[$ John fed $x]]$.

Therefore, the operator only is incompatible with the interpretation of incompleteness because it results in ALL the contextually salient propositions receiving a focus value. Notably, the operator has this effect only when it is [-D-linked] as only in this case the operator cannot be construed as part of the narrow focus of the sentence and must act as a marker of contrast on the VF. A [+D-linked] operator, in contrast, can be construed as applying to every member of the set to which the [-presupposed] constituent belongs, as in (61) and (62) where it is possible to imagine a set of poets in which all members are modified by only, as in only $20^{\text {th }}$ century poets, only $19^{\text {th }}$ century poets, only $18^{\text {th }}$ century poets etcetera. Unsurprisingly, such a strategy allows for selection out of a set of alternatives and therefore for the interpretation of narrow focus. Consequently, in a context that does not license a contrastive VF, a [+D-linked] operator only can be part of a CT:

[Who only reads $20^{\text {th }}$ century poets?]CONTEXT

Mary only reads $19^{\text {th }}$ century poets (but I'm not sure who only reads $20^{\text {th }}$ century poets)

Who only reads poets of one particular century? I

Who only reads $20^{\text {th }}$<smiles>[2H][Pb]([2H])([O-])[O-]</smiles>

Who only reads $19^{\text {th }}$

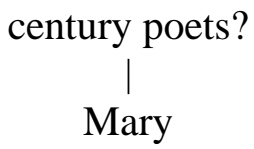

Who only reads $18^{\text {th }}$ century<smiles>O=C(O)OC(F)(F)F</smiles>

The reply in (61) has a CT/FOC structure, with NIF on the subject and CT on the object containing the [+D-linked] operator. Since the operator cannot affect the discourse by providing a focus value for the contextual proposition, the interpretation of incompleteness is attainable.

\subsubsection{Incompatibility with expanding focus operators}

In general sentences hosting a CT are incompatible with expanding operators such as universal and negative quantifiers because these have an effect on the availability of an answer to the superquestion and subsequently to ALL the subquestions. Thus, UNIVERSAL QUANTIFIERS that modify a [-presupposed; +contrastive] constituent alter the sentence in such a way that it provides a POSITIVE answer to the superquestion and therefore to all the subquestions it dominates, including the one in the context (see (63a) and (64)). Hence, no interpretation of incompleteness is available (see (63b)), as the question in the context receives a (positive) answer. Moreover, CF is also incompatible with this strategy (see (63c)), as all the subquestions have the same truth-value (true) on the verum focus and the latter fails to be contrastive. ${ }^{47}$ 
(63)

[Did John feed the cat?] CONTEXT

(a) Yes, John fed all the animals /everyone (including the cat).

(b) \# John fed all the animals (but I don't know if John fed the cat)

(c) \# (No), John fed all the animals (not the cat)

$$
\text { Did John feed the animals? => YES }
$$

Did John feed the cat? Did John feed the dog?

Did John feed the horse?<smiles>C[AsH][AsH]</smiles>
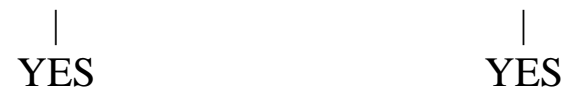

Assuming that a sentence containing a universal quantifier has the semantics given in (65), it is expected that neither (50) nor (51) is compatible with it, as they both require that there exists an entity that is an element of the set of animals and that there exists a world within $(\operatorname{Dox}(s))$ in which it is not true that John fed this entity, whereas (65) demands that the proposition John fed $x$ is true for every entity that is an element of the set of animals.

$$
\forall x[x \in\{\text { a cat, a dog, a horse, } \ldots\} \text { [John fed } x]] .
$$

However, whenever the universal quantifier is [+D-linked], it may be construed as contained in every member of the set of alternatives. In this case, its semantic effect of providing a focus value for ALL contextually salient propositions becomes neutralized:

(66) [Who's read all the books by Dostoevsky?]CONTEXT

Boris has read all the books by Shinkarev (but I'm not sure who's read all the books by Dostoevsky)

Who's read all the books by one particular author?

Who's read all the books

$$
\text { Who's read all the }
$$

Who's read all the books by
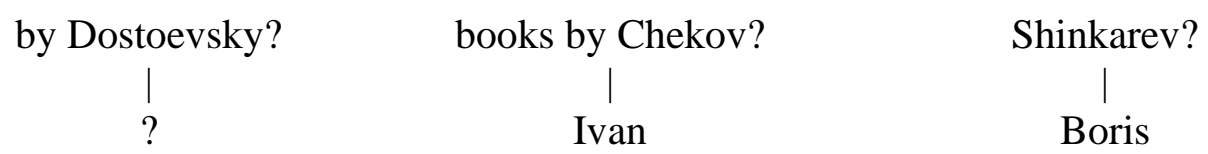

In (66) and (67), it is possible to imagine a set of all books in general that contains subsets of all books by Shinkarev and all books by Dostoevsky etcetera. Consequently, selection out of a set of alternatives and therefore the interpretation of narrow focus becomes possible for the constituent containing a [+D-linked] all.

Unsurprisingly, CTs are compatible with the discourse-tree in (67) because the expanding effect is neutralized here just as the delimiting effect was neutralized in the tree in (62). Moreover, $\mathrm{CF}$ is also compatible with such a strategy as it allows for the verum focus to be contrastive (see (68) where all cats and all dogs can be construed as members of the set of all animals).

$$
\text { John fed all the dogs, not all the cats. }
$$


The discourse strategy making use of NEGATIVE QUANTIFIERS, on the other hand, affects the reply in such a way that it provides a NEGATIVE answer to the superquestion and therefore to all the subquestions it dominates, including the one in the context (see (69a) and (70)). Hence, no interpretation of incompleteness is available (see (69b)) because the question in the context receives an answer.

A sentence with a contrastive VF, on the other hand, is compatible with this strategy (see (69c)) because the proposition John fed no animals does stand in opposition to John fed the cat. Consequently, the proposition in the context and the one in the reply have opposite truth-values and VF is indeed contrastive in the reply.

[Did John feed the cat?]CONTEXT

(a) No, John fed no animals/no one (including the cat).

(b) \# John fed no animals (but I don't know if John fed the cat)

(c) (No), John fed no animals.

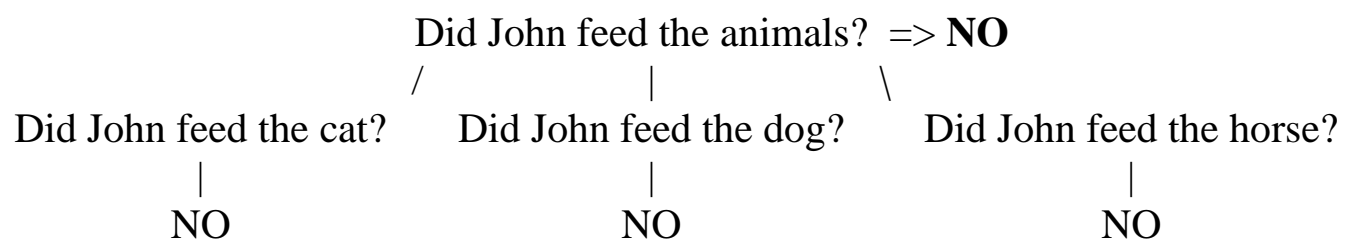

Assuming that a sentence containing a negative quantifier has the interpretation given in (71), it is expected to be compatible with the speaker's beliefs given in (50) but not (51), as the latter requires that there exists an entity that is an element of a set of animals and that there exists a world $w$ within $(\operatorname{Dox}(w))$ in which it is true that John fed this entity, whereas (71) demands that the proposition John fed $x$ is false for every entity that is an element of the set of animals.

$$
\forall x[x \in\{\text { a cat, a dog, a horse, } \ldots\} \neg[\text { John fed } x]]
$$

The strategy of contextual neutralization that can be applied to the delimiting focus operator and to universal quantifiers is unavailable for negative quantifiers because of the latter's direct association with the negative interpretation. To be precise, a question containing a negative quantifier cannot serve as a superquestion dominating a number of subquestions because a negative quantifier cannot act as a superset. A superset can be represented either by a plural noun with the interpretation that allows for subsets, or a wh-phrase that opens a semantic set. A negative quantifier, on the other hand, refers to an empty set. That is, while all animals can form a superset for all cats and all dogs; and only smelly animals can form a superset for only smelly cats and only smelly dogs; no animals cannot form a superset for no cats and no dogs. In other words, negative quantifiers fail to be construed as belonging to any sort of set of alternatives. It is therefore expected that negative quantifiers can never be contained in a constituent with the interpretation of narrow $\mathrm{CF}$ in any type of construction. ${ }^{48}$

\section{CONCLUSION}

The above analysis supports the view that the notion of contrastive topic should be reduced to that of contrastive focus. CTs and CFs are both associated with identical 
interpretative features, which results in their identical syntactic behaviour in Russian. The interpretive difference between the structures that host $\mathrm{CT}$ and $\mathrm{CF}$ is due to the nature of an additional focused element present in the sentence. Thus, a sentence hosting what is traditionally referred to as a CT additionally contains a NIF. The latter provides a focus value for an alternative proposition but fails at providing a focus value for the proposition in the context. The fact that the proposition in the context is left without a focus value results in the interpretation of incompleteness characteristic of Top/Foc sentences.

A sentence hosting what is conventionally analysed as $\mathrm{CF}$, conversely, contains a contrastive verum focus. This type of focus not only provides a truth-value for the alternative proposition but also treats the proposition in the context as having a contrasting truth-value. As both propositions receive a focus value, no questions are left unanswered and no interpretation of incompleteness arises. Instead, the presence of opposite truth-values results in the interpretation of counter-assertion.

Therefore, both CT and CF should be collapsed under one notion of CF that can occur in two different types of construction. Depending on the nature of the additional non-presupposed element present in the sentence that hosts a $\mathrm{CF}$, two different interpretations arise.

The hypothesis that both notions, CT and CF, are associated with the features [-presupposed] and [+contrastive] successfully captures the observation that only these two notions can be associated with contrastive interpretation. Rather than claiming that Topics and Foci can be enriched to yield contrastive interpretation, we can now simplify the grammar by stating that any non-presupposed constituent can be contrastive. This outcome is not as strong as stating that Focus is always contrastive - because, as above illustrated, [-presupposed] can be [-contrastive] - but it entails that contrast is always non-presupposed. Indeed, according to the definition of contrast proposed here, a contrastive constituent always conveys the non-presupposed information that it belongs to a pragmatic set of alternatives. Consequently, even when no additional nonpresupposed information is communicated by this constituent, it still must be analysed as [-presupposed].

\section{REFERENCES}

Anderson, Stephen R. 1969. West Scandinavian vowel systems and the ordering of phonological rules. Ph.D. dissertation, MIT.

Bailyn, John F. 2004a. Generalized Inversion. Natural Language and Linguistic Theory $22,1-49$.

Bolinger, Dwight. 1961. Contrastive accent and contrastive stress. Language 37.1, 8396.

Brun, Dina. 2001. Information structure and the status of NP in Russian. Theoretical Linguistics 27, 109-35.

Bryzgunova, Elena. 1971. O smyslorazlichitel'nyh vozmozhnostyah russkoj intonatsii. Voprosy jazykoznanija 4, 42-51.

Bryzgunova, Elena. 1981. Zvuk i intonatsija russkoj rechi. Moscow: Russkij Yasyk.

Büring, Daniel. 1997. The Meaning of Topic and Focus - The 59th Street Bridge Accent. London: Routledge.

Büring, Daniel. 2003a. On D-Trees, Beans and B-Accents. Linguistics \& Philosophy $26.5,511-545$. 
Büring, Daniel \& Katharina Hartmann. 2001. The syntax and semantics of focus-sensitive particles in German. Natural Language and Linguistics Theory 19.2, 229-281.

Chafe, Wallace L. 1976. Givenness, contrastiveness, definiteness, subjects, topics, and point of view. In C.N. Li (ed.) Subject and Topic, 25-55. New York, San Francisco and London: Academic Press.

Chomsky, Noam. 1995. The minimalist program. Cambridge, MA: MIT Press.

Craenenbroeck, Jeroen van (ed.). 2009. Alternatives to cartography. Berlin: Mouton de Gruyter.

Dretske, Fred J. 1972. Contrastive statements. The Philosophical Review 81, 411-437.

Halliday, Michael. 1967. Notes on transitivity and theme in English - Parts 1 \& 2. Journal of Linguistics 3, 37-81, 199-244.

Hara, Yurie \& Robert van Rooij. 2007. Contrastive topics revisited: A simpler set of topic-alternatives. Presentation at NELS, University of Ottawa.

Heim, Irene. 1992. Presupposition projection and the semantics of attitude verbs. Journal of Semantics 9, 183-221.

Ionin, Tania. 2001. Scope in Russian: Quantifier movement and discourse function. Ms., MIT.

Irurtzun, Aritz. 2007. The grammar of focus at the interfaces. Ph.D. dissertation, Euskal Herriko Unibertsitatea.

Jackendoff, Ray S. 1972. Semantic interpretation in generative grammar. Cambridge, MA: MIT Press.

King, Tracy H. 1995. Configuring topic and focus in Russian. Stanford, CA: CSLI Publications.

Kiparsky, Paul. 1973. 'Elsewhere' in phonology. In Stephen R. Anderson \& Paul Kiparsky (eds.), A Festschrift for Morris Halle, 93-106. New York: Holt, Rinehart and Winston.

Kiss, Katalin É. 1998. Identificational focus versus information focus. Language 74.2, 245-273.

Kratzer, Angelika. 2004. Interpreting focus: Presupposed or expressive meanings? A comment on Geurts and van der Sandt. Theoretical Linguistics 30, 123-136.

Krifka, Manfred. 2008. Basic notions of information structure. Acta Linguistica Hungarica 55, 243-276.

Krylova, Ol'ga \& Serafima Khavronina. 1988. Word order in Russian. Moscow: Russkij jazyk.

Lambrecht, Knud. 1994. Information structure and sentence form. Cambridge: Cambridge University Press.

Lee, Chungmin. 2003. Contrastive topic and/or contrastive focus. In William McClure (ed.), Japanese/Korean Linguistics 12, 352-364. Stanford, CA: CSLI Publications.

Molnár, Valéria. 2002. Contrast from a contrastive perspective. In Hilde Hasselgård, Stig Johansson, Bergljot Behrens \& Cathrine Fabricius-Hansen (eds.), Information structure in a cross-linguistic perspective, 147-161. Amsterdam \& New York: Rodopi.

Neeleman, Ad, Elena Titov, Hans van de Koot \& Reiko Vermeulen. 2009. A syntactic typology of topic, focus and contrast. In van Craenenbroeck, J. (ed.), 15-51.

Neeleman, Ad \& Elena Titov. 2009. Focus, contrast, and stress in Russian. Linguistic Inquiry 40.3, 514-524.

Neeleman, Ad \& Hans van de Koot. 2008. Dutch scrambling and the nature of discourse templates. Journal of Comparative Germanic Linguistics 11, 137-189. 
Neeleman, Ad \& Hans van de Koot. In preparation. Theta theory: In defence of Plan B. Ms., University College London.

Neeleman, Ad \& Reiko Vermeulen (eds.). Forthcoming. A flexible theory of topic and focus movement. Berlin: Mouton de Gruyter.

Neeleman, Ad \& Reiko Vermeulen. Forthcoming. The Syntactic Expression of Information Structure. In Ad Neeleman \& Reiko Vermeulen (eds.), 1-38.

Pereltsvaig, Asya. 2000. Topic and focus as linear notions: evidence from Italian and Russian. Ms. McGill University.

Reinhart, Tanya. 1982. Pragmatics and linguistics. An analysis of sentence topics. Philosophica 27, 53-94.

Richards, Norvin. 2008. Can A-scrambling reorder DPs? Ms., MIT.

Rochemont, Michael S. \& Peter W. Culicover. 1990. English focus constructions and the theory of grammar. Cambridge: Cambridge University Press.

Rooth, Mats. 1985. Association with focus. Ph.D. dissertation, University of Massachusetts, Amherst.

Rooth, Mats. 1992. A theory of focus interpretation. Natural Language Semantics 1, $75-116$.

Sauerland, Uli. 2005. Contrastive topic: A reductionist approach. Ms., ZAS, Berlin.

Schwarzschild, Roger. 1999, 'Givenness, AVOIDF and other Constraints on the Placement of Accent', Natural Language Semantics 7, 141-177.

Titov, Elena. 2007. Pragmatic effects on Russian word (dis)order: Evidence from syntactic and semantic reconstruction. Ms. UCL.

Titov, Elena. 2008. Word order variation in Russian thetic and categorial statements. Ms. UCL.

Titov, Elena. Forthcoming. Encoding focus and contrast in Russian. In Ad Neeleman \& Reiko Vermeulen (eds.), 119-155.

Tomioka, Satoshi. 2010. A scope theory of contrastive topics. Iberia 2, 113-130.

Wagner, Michael. 2008. A compositional analysis of contrastive topics. The North East Linguistic Society (NELS) 39, 1-14.

Wagner, Michael. 2009. Focus, topic, and word order: A compositional view. In Jeroen van Craenenbroeck (ed.), 53-86.

Wagner, Michael. To appear. Contrastive topics decomposed. Ms., McGill University.

Yabushita, Katsuhiko. 2008. A new approach to contrastive topic: Partition semantics and pragmatics. In Tova Friedman \& Satoshi Ito (eds.), Proceedings of SALT XVIII, 747-764. Ithaca, NY: Cornell University.

Yokoyama, Olga. 1986. Discourse and word order. Amsterdam: John Benjamins.

Author's address: $\quad$ Research Department of Linguistics,

Division of Psychology and Language Sciences,

University College London,

Chandler House (room 102),

2 Wakefield Street,

London WC1N 1PF,

United Kingdom,

e.titov@ucl.ac.uk

\section{FOOTNOTES}




\begin{abstract}
${ }^{1}$ Material from this paper was presented at the workshop on New Approached to Russian Syntax that took place on 2 June 2010 at Rijksuniversiteit Groningen as part of the TABU Dag conference. I would like to thank the audience for useful comments. I would also like to thank Klaus Abels, Nathan Klinedinst, Rob Truswell, Hans van de Koot and Reiko Vermeulen, as well as three anonymous reviewers, for detailed comments on this paper. This research is supported by the AHRC.

${ }^{2}$ The present paper concentrates on nominal CTs and CFs. However, the analysis can be extended to include $\mathrm{AP}, \mathrm{PP}$ and predicate CTs and CFs.

${ }^{3}$ Neeleman \& Titov (2009) refer to the more familiar notion of focus.

${ }^{4}$ The focused constituents in (7) must surface in clause final position unless they are enriched with emphatic interpretation (Krylova \& Khavronina 1988). Emphatic focus is analyzed here as [+contrastive], which accounts for the fact that it is allowed to undergo A'-fronting in Russian.

${ }^{5}$ Admittedly, some authors attempt to derive pragmatic presupposition from semantic presupposition projection. However, as argued by Kratzer (2004), the two terms describe quite different phenomena, suggesting that pragmatic presupposition and presupposition projection are separate linguistic notions.

${ }^{6}$ Importantly, what is being referred to here as presupposed must be distinguished from discourse-anaphoric - an interpretation that can be captured by the $[ \pm \mathrm{D}$-linked] feature. Although in most cases presupposed material is [+D-linked] and non-presupposed [-D-linked], as in (7), non-presupposed constituents may contain discourse-anaphoric material. In fact, the entire non-presupposed constituent can be discourseanaphoric, as shown in (i) (see also Rochemont \& Culicover (1990) and Schwarzschild (1999) for an analysis of discourse-anaphoric focus).
\end{abstract}

[Who kissed John's wife?] $[\text { John }]_{\text {FOC }}$ kissed John's wife.

${ }^{7}$ Rochemont \& Culicover 1990 reject the term 'presupposed' on the basis of its ambiguity and replace it with 'c(ontext)-construable'. However, the latter notion fails to distinguish pragmatic presupposition from discourse-anaphoricity.

${ }^{8}$ Notably, the difference between the arguments in the [ \pm presupposed] feature licenses an A-scrambled OVS structure even when both arguments are <+D-linked> (see (i) below), further supporting the information-structural distinction between pragmatic presupposition and discourse-anaphoricity.

(i) [Who kissed Ivan's wife?] CONTEXT Russian

$\begin{array}{llll}\text { Ženu Ivana } & \text { poceloval } & {[\text { Ivan }]_{\mathrm{NIF}}} & \mathrm{OV}[\mathrm{S}]_{\mathrm{NIF}} \\ {[\text { Ivan's wife]-ACC }} & \text { kissed } & \text { Ivan } & \end{array}$

'Ivan kissed Ivan's wife.'

${ }^{9}$ Ionin (2001) uses examples like (i) to argue that anaphoric binding is impossible in Russian.
(a) * Roditeli parents-NOM
(b) * Detej 1 children ACC

$\begin{array}{ll}\text { drug druga } & \text { videli } \\ \text { each other-GEN } & \text { saw } \\ \text { videli } & \text { roditeli } \\ \text { saw } & \text { parents-NOM }\end{array}$
$\operatorname{detej}_{1}$
children-ACC drug druga ${ }_{1}$ each other-GEN

However, what seems to be at stake here is that the Russian reciprocal resists being embedded in an animate argument carrying the most prominent $\theta$-role in the predicate's argument structure. This accounts for the ungrammaticality of the examples in (i) and correctly predicts that example (8b) should become ungrammatical if the nominative argument is replaced by an animate NP (Klaus Abels p.c.):

(ii)
* Kollegi colleagues-NOM
(b) $*$ Milicionerov $_{1}$ milicia-men-ACC
drug druga $_{1} \quad$ ubili $\quad$ milicionerov ${ }_{1}$ each other-GEN killed milicia-men-ACC

${ }^{10}$ In (10a), the apparent wide scope reading of the existential quantifier is accessible due to the availability of a specific interpretation for the indefinite.

11 Space does not permit me to discuss Richards' (2008) 'tucking in' analysis of A-scrambling.

${ }^{12}$ It must also be stipulated that this type of A-movement is not subject to locality restrictions, as it allows for A-movement of NPs/DPs across c-commanding NPs/DPs. 
${ }^{13}$ As pointed out by an anonymous reviewer, if the assumed interpretative features are not relevant to the syntactic computation, an A-movement analysis of A-scrambling must assume a Move-alpha type of approach (cf. Chomsky 1986), in violation of a strict version of Last Resort. Under an A-movement analysis, crossing of an argument by another is structurally encoded by a trace. Under a base-generation approach, it is signaled by the relative thematic prominence of arguments: if the argument that is structurally higher is THEMATICALLY less prominent than the one that is structurally lower, this indicates a marked order of merger (see Neeleman \& van de Koot (in preparation) for an analysis in this spirit).

14 As pointed out by an anonymous reviewer, on an A-movement analysis it must be assumed that movement is always leftward if the surface order and scope facts are to be accounted for.

${ }^{15}$ For reasons for analyzing focus in Top/Foc structures as NIF see section 3.

16 That A'-moved [-presupposed] constituents obligatorily reconstruct is apparent from examples like (i) below, which are unambiguous: the indefinite cannot be dependent on the universal. For further discussion, see Neeleman \& van de Koot 2008. The same judgment holds for Russian (contra Bailyn 2001; see (ii) for $\mathrm{A}^{\prime}$-moved CF and (11b) in the main text for A'-moved CT).

(i) [Every boy $]_{\mathrm{CF} 1}$ two girls said [that Mary kissed $\left.t_{1}\right]$

(ii) $[\text { Každogo mal'čika }]_{\mathrm{CF} 1}$ dve devočki xotjat, [čtoby Maša pocelovala $\left.t_{1}\right]$ every boy-ACC two girls want that Masha kissed

'Two girls want every boy to be kissed by Masha.' $\quad \exists>\forall ; * \forall>\exists$

17 The ideas presented in this subsection are also discussed in Titov (forthcoming).

${ }^{18}$ Lee (2003) argues that an answer to a disjunctive contextual question, as in (16), contains a CF. However, if the focus were contrastive in the reply in (16), it would be expected to undergo A'-movement in Russian and it would be marked with IK2. Yet, the most neutral answer to the disjunctive question in (16) keeps the object in situ, with IK1 assigned to it.

Importantly, the context in (16) does not FORCE a non-contrastive reading of the object in the reply; it only favors it in the same way as a context of a wh-question favors a reply with a NIF. It is, however, possible to use a variety of strategies to add contrastive reading to the object. Thus, the object can be enriched with EMPHATIC contrastive interpretation (see the discussion around (20)). It is also possible for the reply to the disjunctive question in (16) to override the construal of cat and $d o g$ as members of a set of alternatives that have distinct properties with respect to Ivan fed $x$. As soon as the option of cat and dog having the same property is considered available within the given context, it becomes possible for the reply to activate a contrastive interpretation on the object, as in (i) where the reply overrides the presupposition that alternative properties hold of cat and $d o g$ and allows for the reading where Ivan fed the dog as well. Notably, in the neutral answer in (16) this reading is impossible.

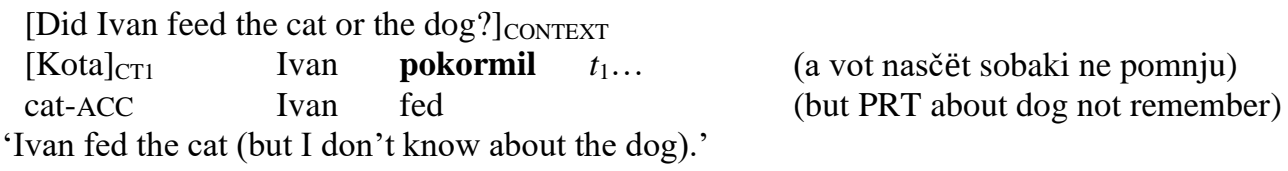

${ }^{19}$ Notably, if the contextual question in (16) introduced other members of the set of alternatives but not cat, whereas the reply conveyed that cat also belongs to this set, the object would be construed as [+contrastive] because in that case, the interpretation that the object belongs to a set of alternatives would be activated by the reply despite the set being introduced by the context:

(i)

[Did Ivan feed the hamster or the dog? $]_{\text {CONTEXT }}$
Ivan $[\text { kota }]_{\mathrm{CF}}$ pokormil (a ne xomjaka i ne sobaku)
Ivan cat-ACC $\quad$ fed $\quad$ (and not hamster and not dog)
Ivan fed the cat (not a hamster or a dog).'

${ }^{20}$ As can be seen from (17), CFs typically move to a position immediately before the verb, whereas CTs usually occupy positions further to the left in Russian. As structures with distinct interpretations must be distinguished either through prosody or context or surface structure, in an ambiguous context, as in (17), in the absence of prosodic encoding (i.e. in written language), structural encoding is the only option. However, when prosody is available (i.e. in spoken language), CT and CF can both move to a sentence-initial or to an intermediate position as long as CT is marked with IK3 and CF with IK2. 
${ }^{21}$ The fact that knowledge about the scalar position of EF must be shared by the interlocutors is confirmed by the observation that whenever the hearer is unaware of it, a sentence with a moved focus is perceived as odd in contexts that do not license contrast and requires clarification (i.e. the speaker is perceived as being either surprised or annoyed for no apparent reason).

${ }^{22}$ This subsection is partially based on Neeleman \& Titov (2009).

${ }^{23}$ The judgments in the main text presuppose that the constituents marked as CF bear IK2, while the rest of the sentence is destressed. In Top/Foc structures, constituents conveying the interpretation of CT bear IK3, whereas NIF is marked with IK1. For further discussion, see Bryzgunova 1971, 1981, Yokoyama 1986, Pereltsvaig 2000, and Krylova \& Khavronina 1988.

${ }^{24}$ Movement is said to be licensed rather than triggered by the [+contrastive] feature, since the relevant type of A'-scrambling is optional in many languages including Russian. For further discussion of the issue see Neeleman \& van de Koot 2008 and Neeleman et al. 2008.

${ }^{25}$ The analysis of focus in Top/Foc structures as NIF accounts for the observation made by Büring (2003) that it is not (easily) interchangeable with the CT:

[What did the pop stars wear?]

(a) The $[\text { female }]_{\mathrm{CT}}$ pop stars wore $[\text { caftans }]_{\mathrm{NIF}}$

(b) *The [female $]_{\mathrm{NIF}}$ pop stars wore $[\text { caftans }]_{\mathrm{CT}}$

The CT in (i) selects a subset of female pop stars from a contextually salient set of pop stars, whereas the NIF provides a value for $x$ in The pop stars wore $x$. The distinct pragmatic functions of the CT and the NIF licensed by the context result in the degraded status of (ib). However, as can be seen from (ii), examples with non-partial CTs allow for a Topic/Focus swap more easily:

(ii) [Čto eli gosti?] CONTEXT

'What did the guests eat?'

$\begin{array}{llll}\text { Salat } & \text { el } & \text { tol'ko } & \text { Boris... } \\ \text { salad-ACC } & \text { ate } & \text { only } & \text { Boris }\end{array}$

'As for the salad, only Boris ate it...'

26 Admittedly, focus in TOP/FOC structures can be interpreted as emphatic, as this type of contrast makes reference to a scalar position in an implicit set of alternatives and does not have an effect on the availability of an alternative focus value in the discourse.

27 Space does not permit me to discuss cases of A-scrambling in all-focus constructions licensed on the basis of interpretations not discussed in the present paper.

28 The motivation for movement of the object to SpecIP can be the EPP condition, which, according to Bailyn (2004a), can be satisfied by any XP in Russian.

${ }^{29}$ To make the opposition possible, a delimiting focus sensitive operator only can be used in (27). In that case, feeding only the cat can stand in opposition to feeding all the animals. The discourse strategies that make use of focus sensitive operators are discussed in detail in section 5 .

${ }^{30}$ Incidentally, for the object in (28) to be interpreted as NIF, it would have to occur in the context of a question like Who did you feed?.

${ }^{31}$ All the sentences in (i) below have distinct IS despite occurring in the same context:

(i)

[What's wrong?] CONTEXT
a. John only showed my book to Mary (and I wanted him to show it to Sue as well).
b. John only showed my book to Mary (and I wanted him to show my articles as well).
c. John only showed my book to Mary (and I wanted him to show your book as well).
d. John only showed my book to Mary (and I wanted him to read it to her as well).

32 The data in (32) and (33) demonstrate that CT and CF can be licensed by the same context, which seems to contradict the analysis in Lee (2003) where sentences containing a CT are taken to be introduced by a conjunctive question and sentences hosting a CF by a disjunctive question. However, neither a conjunctive nor a disjunctive question FORCES a particular interpretation on the focused constituent in the reply. It can only FAVOR it. Thus, a disjunctive yes/no-question favors the construal of the VF in the reply as contrastive, as it activates contrastive interpretation on the conjuncts, i.e. they are interpreted as having alternative properties. The most natural reply to such a question activates the interpretation that the alternative proposition has a contrasting truth-value (see (16)). As expected, a CT cannot co-occur with a CONTRASTIVE VF, in line with Lee's (2003) observations. Yet, as demonstrated in footnote 18, it is possible to override 
the contrastive construal of the conjuncts in a disjunctive question, in which case a CT can occur in its context. Likewise, CFs can occur in the narrow-down context of a conjunctive question (see (i)), as long as the delimiting operator is used in order to facilitate a contrastive reading of the VF, whereas REPLACING CTs cannot occur in such a context. Importantly, Lee's (2003) observations with respect to conjunctive vs. disjunctive contextual questions fall out from the current analysis, as the former favor a reply with a [-contrastive] VF and the latter with a [+contrastive] VF.

(ii) [Did Ivan feed the cat and the dog? $]_{\text {CONTEXT }}$

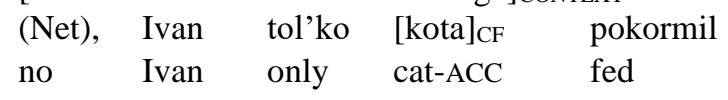

'(No), Ivan only fed the cat.'

${ }^{33}$ A Top/Foc sentence with a prosodically unrealized VF, as in (32b), is distinguished from a sentence containing a CF by the virtue of CT carrying a B-accent. However, in Top/Foc sentences with an overt NIF, at least SOME speakers can mark a CT with a falling contour (Alanah McKillen p.c.), leaving the burden of disambiguation to the presence/absence of prosodic marking of VF.

${ }^{34}$ As mentioned in footnote 29, it is possible to achieve [+contrastive] reading for the VF in (27) and (39) by applying a delimiting focus sensitive operator only to the CF. This results in the construal of the cat as the only entity for which the property of being fed applies. Consequently, the remaining subquestions receive negative answers and the superquestion in the context obtains a negative truth-value.

${ }^{35} \mathrm{I}$ am assuming that a superset in the superquestion can be represented by either a wh-phrase that opens a semantic set (see (37) and (38)) or a plural noun that generalizes over a set (see (39)).

36 The data on which the analysis relies involves the so-called REPLACING strategy (as in (32) and (33)) but can be extended to include the NARROW-DOWN strategy, as in (i), as long as the CFs are embedded under the delimiting focus operator, which facilitates contrastive reading on the VF. Consequently, CT and CF can both be PARTIAL as shown in (ii):

(i)

[Did you feed the cat and the dog?]

(a) I fed [the cat $]_{\mathrm{CT}}$ (but I don't remember about the dog)

(b) No, I only fed [the cat $]_{\mathrm{CF}}$ (but I forgot to feed the dog)

[Did the dancers wear kaftans?] CONTEXT

(a) The [female $]_{\mathrm{CT}}$ dancers did wear kaftans (but I'm not sure about the male dancers)

(b) No, only the [female $]_{\mathrm{CF}}$ dancers wore kaftans (the male dancers wore lederhosen)

37 As already mentioned in footnote 33, some native speakers of English allow A-accent on CT in unambiguous contexts, suggesting that when the IS of a sentence is disambiguated as a TOP/FOC structure by context, prosodic disambiguation becomes redundant. The fact that $\mathrm{CT}$ can carry the same prosodic marker as CF further supports the view that $\mathrm{CT}$ and $\mathrm{CF}$ is one and the same IS notion.

38 (41) illustrates that a CF may co-occur with a NIF (or a non-contrastive VF), which results in the interpretation of incompleteness, or with a CVF resulting in the interpretation of opposition. Importantly, (41) does not rule out structures of the following type: CF/CF/CVF or CF/CF/NIF. What should be impossible is a sentence of the type CF/NIF/CVF (see (i)), as it contains both NIF and CVF and the status of the CF cannot be identified.

$$
\begin{aligned}
& \text { [What did Bill eat? ]CONTEXT } \\
& \left.*^{*} \mathrm{No},[\text { Fred }]_{\mathrm{CF}} \text { ate } \text { CVF }_{\text {C the soup }}\right]_{\mathrm{NIF}}
\end{aligned}
$$

${ }^{39}$ From clause final position NIF can spread onto the entire CP if the sentence contains no background.

${ }^{40}$ As pointed out by Hans van de Koot (p.c.), it is possible to have a sentence with a CT even when a contextual proposition receives a focus value as long as there is another proposition in the discourse that is left without a focus value. In other words, what is crucial for the interpretation of incompleteness is the presence of a proposition in the discourse with no focus value.

${ }^{41}$ I am very grateful to Rob Truswell for pointing this out to me.

${ }^{42}$ The idea behind (51) is similar to the analysis in Hara \& van Rooij (2007), for whom the absence of the relevant knowledge on the part of the speaker is also required for the interpretation of CT/FOC structures. Yabushita (2008) criticizes Hara \& van Rooij's (2007) analysis by pointing out that the speaker might possess the relevant knowledge but chooses to be secretive about it. However, the interpretation of a $\mathrm{CT} / \mathrm{FOC}$ construction must not be confused with the specific situation in which it is used. A CT/FOC 
structure does indeed convey a lack of knowledge on behalf of the speaker but this interpretation is compatible with the situation where the speaker is being secretive or untruthful and uses this construction to hide the truth out of politeness or to deceive the hearer.

${ }^{43}$ Whenever the NIF in a CF/NIF sentence is assigned to a constituent, as in (i), the semantic notation must include two variables, as in (ii), where the function (corresponding to the background in (i)) is assumed to apply to the focus and to members of the set of alternatives in the overtly specified order:

(i) [What did John buy?]CONTEXT

[Mary $]_{\mathrm{CT}}$ bought a [Toyota $]_{\mathrm{NIF}}$ (but I don't know about John).

(ii) (a) $\langle\lambda x \lambda y[x$ bought $y]$ Mary, Toyota, $\{$ John, Mary, Sue,... $\}\{$ Toyota, Volkswagen, Bentley, ... $\}>$

(b) $\exists x\left[x \in\{\right.$ John, Mary, Sue $\ldots\} \& \mathrm{x} \neq \operatorname{Mary} \& \exists w[w \in \operatorname{Dox}(s) \&[x$ bought Toyota $]] \& \exists w^{\prime}\left[w^{\prime}\right.$ $\in \operatorname{Dox}(s) \& \neg[x$ bought Toyota $]]]$.

Note that since the focus in CT/FOC structures is a NIF, (iib) has nothing to add to its interpretation. The semantics of NIF is already captured by (iia).

${ }^{44}$ By narrow focus, I mean focus that is assigned to a syntactic constituent and that does not involve focus spreading onto the entire clause or VF.

${ }^{45}$ Admittedly, whenever a contrastive focus embedded under only undergoes A'-fronting, the delimiting operator has to linearly precede it. If only is not included in the interpretation of focus and can therefore not be part of the fronted constituent, an alternative account of this observation is required (Hans van de Koot, p.c.). However, the fact that in a variety of languages, including English, only can occur in adverbial rather than adnominal position suggests that focus particles can adjoin to non-arguments. It is therefore plausible that the delimiting operator adjoins to the root CP in order to c-command a fronted contrastive focus in the aforementioned constructions (see also Büring and Hartmann 2001 for an analysis of German focus particles as consistently adjoining to non-arguments).

46 The fact that phrases including the aforementioned operators cannot be construed as belonging to a set of cars is confirmed by the impossibility of forming a coordinate structure with one conjunct containing one such phrase and the other containing an alternative member of the set of cars:

(i) (a) *John bought a Volkswagen and only a Toyota

(b) * John bought a Volkswagen and no car

(c) *John bought a Volkswagen and all cars

${ }^{47}$ The only way in which the VF in (63c) can be construed as contrastive is by interpreting the contextual proposition John fed the cat as exhaustive (e.g. John only fed the cat). In such a case, the proposition John fed all the animals can stand in opposition to John only fed the cat as the former questions the exhaustive reading of the latter.

${ }^{48}$ If a set of quantifiers of the type $\{$ no $x$, some $x$, all $x\}$ is imagined, then both the negative quantifier and the universal quantifier can be understood as occupying the edge positions on a scale, making the interpretation of EMPHATIC foci available for them. 